\title{
Sympatric prey responses to lethal top-predator control: predator manipulation experiments
}

\author{
Benjamin L Allen ${ }^{1,2^{*}}$, Lee R Allen², Richard M Engeman ${ }^{3}$ and Luke K-P Leung ${ }^{1}$
}

\begin{abstract}
Introduction: Many prey species around the world are suffering declines due to a variety of interacting causes such as land use change, climate change, invasive species and novel disease. Recent studies on the ecological roles of top-predators have suggested that lethal top-predator control by humans (typically undertaken to protect livestock or managed game from predation) is an indirect additional cause of prey declines through trophic cascade effects. Such studies have prompted calls to prohibit lethal top-predator control with the expectation that doing so will result in widespread benefits for biodiversity at all trophic levels. However, applied experiments investigating in situ responses of prey populations to contemporary top-predator management practices are few and none have previously been conducted on the eclectic suite of native and exotic mammalian, reptilian, avian and amphibian predator and prey taxa we simultaneously assess. We conducted a series of landscape-scale, multi-year, manipulative experiments at nine sites spanning five ecosystem types across the Australian continental rangelands to investigate the responses of sympatric prey populations to contemporary poison-baiting programs intended to control top-predators (dingoes) for livestock protection.
\end{abstract}

Results: Prey populations were almost always in similar or greater abundances in baited areas. Short-term prey responses to baiting were seldom apparent. Longer-term prey population trends fluctuated independently of baiting for every prey species at all sites, and divergence or convergence of prey population trends occurred rarely. Top-predator population trends fluctuated independently of baiting in all cases, and never did diverge or converge. Mesopredator population trends likewise fluctuated independently of baiting in almost all cases, but did diverge or converge in a few instances.

Conclusions: These results demonstrate that Australian populations of prey fauna at lower trophic levels are typically unaffected by top-predator control because top-predator populations are not substantially affected by contemporary control practices, thus averting a trophic cascade. We conclude that alteration of current top-predator management practices is probably unnecessary for enhancing fauna recovery in the Australian rangelands. More generally, our results suggest that theoretical and observational studies advancing the idea that lethal control of top-predators induces trophic cascades may not be as universal as previously supposed.

Keywords: Canis lupus dingo, Carnivore conservation, Fauna recovery planning, Ground-dwelling birds, Kangaroo, Poison baiting, Small mammals, Threatened species

\footnotetext{
* Correspondence: benjamin.allen@daff.qld.gov.au

'School of Agriculture and Food Sciences, The University of Queensland,

Warrego Highway, Gatton, QLD 4343, Australia

${ }^{2}$ Robert Wicks Pest Animal Research Centre, Biosecurity Queensland, Tor

Street, Toowoomba, QLD 4350, Australia

Full list of author information is available at the end of the article
} 


\section{Introduction}

Many prey species around the world are threatened or suffering declines in many parts of their ranges due to a variety of interacting biotic, abiotic and anthropogenic causes such as land use change, climatic change, invasive species and novel disease [1-3]. Unbalanced ecosystems with disproportionately high densities of some fauna (e.g. herbivores and mid-sized or mesopredators) can exacerbate the rate of species declines in some cases [4,5]. Apex or top-predators such as lions (Panthera leo), bears (Ursus spp.) or grey wolves (Canis lupus) are expected to stabilise or recalibrate ecosystems by reducing populations of such overabundant species and allowing threatened prey at lower trophic levels to recover [6-8]. Moreover, many toppredators are themselves threatened, in decline or presently absent from large portions of their former ranges, and for this reason alone are worthy of conservation and restoration [9]. Great interest surrounds the recovery and potential use of top-predators as 'natural' and low-cost biodiversity conservation tools $[10,11]$. Consequently, predator management strategies known or perceived to have negative effects on top-predator populations are expected by some to produce outcomes ultimately detrimental to prey species and even vegetation communities at lower trophic levels $[12,13]$. Humans are not detached from these processes given their (often unacknowledged) role as the ultimate 'top-predator' or manipulator of species and ecosystems [14-18].

Though the important role that terrestrial top-predators can sometimes play in structuring food webs and ecosystems through their consumptive (e.g. predation) and nonconsumptive (e.g. fear, competition) effects on sympatric mesopredator and herbivore species is well known [7-9], top-predators are often lethally controlled to protect livestock, managed game and some threatened fauna from top-predator predation (e.g. [19-22]). Lethal control of top-predators is typically achieved through trapping, shooting and/or poisoning in different parts of the world. Lethal control of rare or threatened toppredators is often unacceptable in many cases (e.g. [23]), and knowledge of or expectations about the ecological roles of top-predators is often used to justify calls to cease lethal control of these threatened toppredators (e.g. $[8,24])$. But not all top-predators are rare or in decline. In places where top-predator populations are very common, robust and resilient to control (such as Australia), their strategic lethal control (or periodic, temporary suppression) might facilitate profitable livestock or game production while retaining their important functional roles in limiting, suppressing or regulating overabundant species [25].

Introduced to Australia about 5,000 years ago, dingoes (Canis lupus dingo and hybrids) are a relatively small (typically $12-17 \mathrm{~kg}$ ) but now common and widespread canid top-predator, extant across $\sim 85 \%$ of the continent $[26,27]$. However, some specific dingo genotypes are in decline and worthy of conservation [28-30]. Genetic issues aside, dingoes' distribution and densities are naturally increasing (back into the few remaining areas, $<15 \%$ of Australia, where they were formerly exterminated) despite often being subject to periodic lethal control programs for the protection of livestock and some threatened fauna $[19,27,31]$. Faunal biodiversity conservation is expected by some to be compromised by lethal dingo control through its perceived indirect positive effects on mesopredators and their cascading negative effects on prey (e.g. [32-34]). Snapshot, observational, correlative or desktop studies have sometimes reported negative relationships between dingoes and mesopredators or positive relationships between dingoes and some threatened fauna (reviewed in $[35,36])$. In contrast, long-term and/or experimental studies on the subject have consistently reported that mesopredator populations fluctuate independent of dingoes and dingo control over time ([25,37-39]; see also [40]). Investigation of predator-prey relationships have been a pillar of ecological studies for decades [41], but applied-science studies investigating the indirect in situ responses of prey populations to contemporary top-predator management practices are few $[12,18,22,42,43]$.

The prey response to top-predator control is one of the most important variables of interest where threatened prey persist and extant predators of concern can only be managed through lethal control [42]. In these situations, reliably determining causal factors for changes in prey abundance can only be achieved through carefully designed manipulative experiments conducted at spatial and temporal scales relevant to management $[35,44,45]$. We therefore used a series of predator manipulation experiments - those with the highest level of inference logistically achievable in open rangeland areas $[35,46]$ - to determine (1) whether or not sympatric prey abundances were different between areas that were or were not exposed to top-predator control, (2) whether or not sympatric prey activity levels decreased immediately after toppredator control, and (3) whether or not sympatric prey abundance trends were influenced by top-predator control over time. There are six primary relationships between top-predator control and prey fauna (Figure 1). The relationships (or lack thereof) between mesopredators and dingoes or dingo control (R1, R2 and R4 in Figure 1) were previously reported in Allen et al. [25], and the present study is best understood in conjunction with those results. As an extension to that work, the primary aim of the present study was not to investigate the relationships between dingoes and prey (R5 in Figure 1). Rather, we experimentally assessed whether or not ground-dwelling 


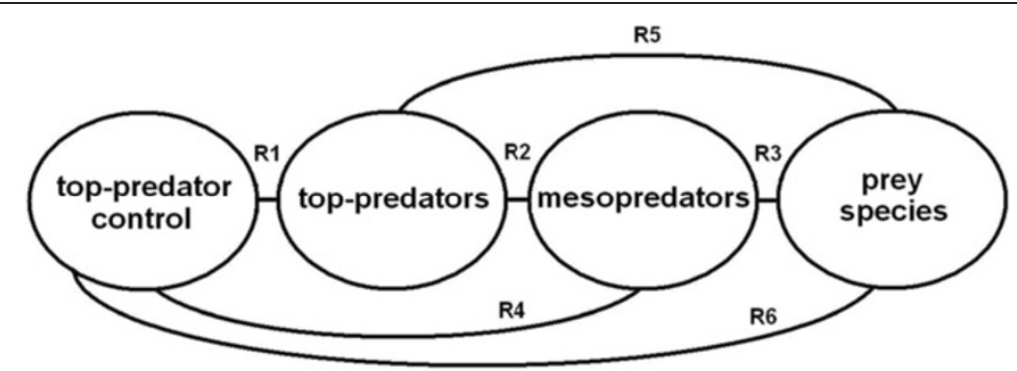

Figure 1 Schematic representation of the six primary relationships of interest (R1-R6) between top-predator control and prey species at lower trophic levels (see [42]).

mammalian, avian, reptilian and amphibian prey populations were influenced by contemporary poison-baiting programs aimed at controlling dingoes (R6 in Figure 1). Comparisons were made between a series of paired poison-baited and unbaited areas monitored over time both before and after multiple baiting events using passive tracking indices (PTI; see Methods for details of study sites and design, prey population monitoring techniques and analytical approaches). These experiments were conducted at nine sites spanning the breadth of the beefcattle rangelands of Australia, comprising one of the largest geographic scale predator manipulation experiments conducted on any species anywhere in the world [43].

\section{Results}

\section{Step 1 - Overall patterns in prey abundance}

Linear mixed model analyses revealed a significant interaction between baiting history (i.e. consistent history, historically baited in both treatments before cessation of baiting in the unbaited area, or historically unbaited in both treatments before baiting commenced in the baited area) and treatment (baited or unbaited) for dingoes, but not for any other predator or prey species (Table 1). This is unsurprising given that baiting programs target dingoes, and as expected, baiting history and treatment were similarly significant as univariate factors influencing dingo PTI (Table 1). Overall mean and median macropod PTI was also different between different baiting histories, but not between baited and unbaited treatment areas. No other predator or prey species or species group showed an interaction, nor did any show a difference in PTI between baited and unbaited areas using this approach (Table 1). However, results from this analysis may obscure true prey responses to baiting given the unique combination of experimental design, sampling effort, land system, treatment size, baiting history, baiting context, baiting frequency, fauna assemblage, rainfall conditions and climate trend effects potentially influencing observed fauna responses to baiting at each site. Thus, results for individual 'site $x$ species' responses to top-predator control are described hereafter to explicitly identify any species- and sitespecific responses to baiting.

Repeated measures ANOVA yielded no indication that PTI values for prey were consistently lower in areas exposed to periodic poison-baiting for dingoes (Table 2). Demonstrable differences in PTI between treatments were found in only 20 of the 67 'site $x$ prey species' combinations with sufficient data; in only 11 of these $(16 \%$ of all cases) was prey PTI lower in baited areas. These 11 cases occurred at different sites for a range of mammals and birds (Table 2). Stratifying the data by season likewise indicated no consistently lower prey PTI values in baited areas (Table 3). Demonstrable differences in PTI between treatments were found in only 29 of the 193 'site $\mathrm{x}$ season $\mathrm{x}$ prey species' combinations with sufficient data; in only 13 of these (7\% of all cases) was prey PTI lower in baited areas. These 13 cases occurred in all seasons except summer, for birds, reptiles and mammals at some sites (Table 3).

\section{Step 2 - Short-term behavioural responses of prey}

A total of 25 baiting events from all sites included postbaiting surveys conducted within four months of baiting from both treatments (mean number of days since baiting $=51$ ). Assessing changes in prey PTI between surveys conducted just prior and subsequent to baiting showed little indication of short-term responses of prey at Mt Owen ( $\mathrm{N}=8$ events), Quinyambie ( $\mathrm{N}=4$ events), Strathmore ( $\mathrm{N}=5$ events) or Todmorden $(\mathrm{N}=5$ events) (Figure 2). An insufficient number of pre- and postbaiting pairs were available to reliably run this analysis for the other sites. Using this approach, demonstrable changes were only found for birds at Strathmore, where PTI values were lower subsequent to baiting (Figure 2).

\section{Step 3 - Longer-term prey abundance trends}

Correlations in longer-term PTI trends between baited and unbaited areas were determined for 62 possible 'site $\mathrm{x}$ prey species' combinations (Table 4). Of these correlations, 33 (53\% of all cases) were demonstrably positive and the remainder were indistinguishable from zero; no 
Table $1 \mathrm{P}$ values obtained from linear mixed model analyses investigating the effects of baiting history (consistent, historically baited in both treatments before cessation of baiting in the unbaited area, or historically unbaited in both treatments before commencement of baiting in the baited area), treatment (baited or unbaited) and their interaction on overall mean $(\mathrm{Mn})$ and overall median (Med) predator and prey PTI at nine sites across Australia

\begin{tabular}{|c|c|c|c|c|}
\hline & Source & Baiting history $(\mathrm{H})$ & Treatment $(\mathrm{T})$ & $\mathrm{T}^{*} \mathrm{H}$ \\
\hline \multirow{2}{*}{ Dingoes } & $\mathrm{Mn}$ & 0.0242 & 0.0001 & 0.0004 \\
\hline & Med & 0.0283 & 0.0001 & 0.0001 \\
\hline \multirow{2}{*}{ Foxes } & $\mathrm{Mn}$ & 0.1200 & 0.1200 & 0.1400 \\
\hline & Med & 0.1000 & 0.2100 & 0.1700 \\
\hline \multirow{2}{*}{ Cats } & $\mathrm{Mn}$ & 0.9500 & 1.0000 & 0.1800 \\
\hline & Med & 0.8000 & 0.6100 & 0.3600 \\
\hline \multirow{2}{*}{ Goannas } & $\mathrm{Mn}$ & 0.8500 & 1.0000 & 0.1800 \\
\hline & Med & 0.7400 & 0.6100 & 0.9300 \\
\hline \multirow{2}{*}{ Birds } & $\mathrm{Mn}$ & 0.5200 & 0.4400 & 0.2800 \\
\hline & Med & 0.5300 & 0.6700 & 0.1200 \\
\hline \multirow{2}{*}{ Rabbits } & $\mathrm{Mn}$ & 0.1900 & 0.5800 & 0.0481 \\
\hline & Med & 0.1800 & 0.7600 & 0.3000 \\
\hline \multirow{2}{*}{ Possums } & $\mathrm{Mn}$ & 0.4600 & 0.3800 & 0.4100 \\
\hline & Med & 0.4500 & 0.3600 & 0.4200 \\
\hline \multirow{2}{*}{ Small mammals } & $\mathrm{Mn}$ & 0.3100 & 0.4100 & 0.6600 \\
\hline & Med & 0.3900 & 0.3200 & 0.7700 \\
\hline \multirow{2}{*}{ Macropods } & $\mathrm{Mn}$ & 0.0185 & 0.9100 & 0.1300 \\
\hline & Med & 0.0336 & 0.7000 & 0.2100 \\
\hline \multirow{2}{*}{ Pigs } & $\mathrm{Mn}$ & 0.5000 & 0.4700 & 0.3600 \\
\hline & Med & 0.4400 & 0.4300 & 0.3800 \\
\hline \multirow{2}{*}{ Echidnas } & $\mathrm{Mn}$ & 0.1300 & 0.3600 & 0.4200 \\
\hline & Med & 0.4200 & 0.3600 & 0.4200 \\
\hline \multirow{2}{*}{ Frogs } & $\mathrm{Mn}$ & 0.5100 & 0.5700 & 0.2700 \\
\hline & Med & 0.4200 & 0.3600 & 0.4200 \\
\hline \multirow{2}{*}{ Hopping-mice } & $M n^{*}$ & 0.4400 & 0.5100 & 0.5000 \\
\hline & Med* $^{*}$ & 0.4200 & 0.4600 & 0.5100 \\
\hline \multirow{2}{*}{ Reptiles } & $\mathrm{Mn} \wedge$ & 0.5400 & 0.4700 & 0.2900 \\
\hline & Med* $^{*}$ & 0.8800 & 0.7000 & 0.1700 \\
\hline
\end{tabular}

Note: $\sim$ df values for History $=2, \operatorname{Site}(H)=6$, Treatment $=1, T^{*} H=2, T^{*} S(H)=6$; ${ }^{*}$ df values for History $=1$, Site $(H)=2$, Treatment $=1, T^{*} H=1, T^{*} S(H)=2$; $\wedge$ df values for History $=1$, Site $(H)=n / a$, Treatment $=1, T^{*} H=1, T^{*} S(H)=4$; insufficient data for koalas and toads.

demonstrably negative correlations were observed. For example, birds were positively correlated between treatments at all sites except Quinyambie and Cordillo. Small mammals were positively correlated between treatments at all sites except Strathmore. Macropods were positively correlated between treatments at Barcaldine, Blackall, Lambina, Mt Owen and Strathmore, but not Cordillo,
Quinyambie, Tambo or Todmorden. No demonstrable correlations between treatments were found for echidnas (Tachyglossus aculeatus) at any site. Of the 33 demonstrable and positive correlations observed, 25 (or $76 \%$ of cases) showed $\mathrm{r}$ values exceeding 0.75 , indicating that the positive correlations observed were typically very strong (Table 4). For example, $\mathrm{r}$ approached 1.0 and $\mathrm{p}=<0.001$ in most correlations for hopping-mice (Notomys spp.) and other small mammals.

Divergence or convergence of PTI trends was assessable for 65 'site $\mathrm{x}$ prey species' combinations. Of these, six suggested a demonstrable increase in PTI in baited areas over time, and only three (birds at Quinyambie, and possums at Mt Owen and Strathmore; $<5 \%$ of all cases) suggested a demonstrable decrease in baited areas over time (Figures 3, 4, 5, 6, 7, 8, 9, 10, 11, 12, 13, 14, $15,16,17,18,19,20)$. No demonstrable changes in PTI differences over time were detected for all other 'site $\mathrm{x}$ prey species' combinations. These data demonstrate that longer-term prey PTI trends were typically unaffected by dingo control, instead fluctuating synchronously in baited and unbaited areas over time (Figures 3, 4, 5, 6, 7, 8, $9,10,11,12,13,14,15,16,17,18,19,20)$.

\section{Predator responses to baiting}

We previously showed that mesopredator suppression by dingoes was not apparent given that European fox (Vulpes vulpes), feral cat (Felis catus) and goanna (Varanus spp.) trends were not negatively correlated with dingoes over time [25]. However, correlations in longerterm predator PTI trends between baited and unbaited areas were determined here for 33 possible 'site $\mathrm{x}$ predator species' combinations (Table 5; see also Figure Two in [25]). Of these correlations, nine were demonstrably positive (27\% of all cases) and the remainder were all indistinguishable from zero. No negative correlations between treatments were detected for any predator at any site (Table 5). The nine demonstrably positive correlations were detected for dingoes, foxes, cats and goannas at different sites (Table 5). Divergence or convergence of predator PTI trends was also assessed here for 35 'site $\mathrm{x}$ predator species' combinations. Of these, cat PTI apparently increased in baited areas at Tambo and Todmorden yet decreased in baited areas at Quinyambie, and fox PTI apparently decreased in baited areas at Todmorden (Figures 12, 13, 14, 15, 16, 17, 18, 19, 20). However, each of these four outcomes seem artificial given that very few cats or foxes were ever observed at these sites (Table 6 and Figure Two in [25]). Regardless, divergence or convergence of trends was not detected for dingoes (or goannas) at any site (Figures 12, 13, 14, 15, 16, 17, $18,19,20)$, demonstrating that (1) dingo PTI trends were unaffected by dingo control over time and (2) observed convergence or divergence of mesopredator PTI 
Table 2 P values obtained from repeated measures ANOVA assessing differences in overall mean prey PTI (all surveys pooled) between baited and unbaited areas at nine sites across Australia (see Table 3 for seasonal breakdown)

\begin{tabular}{|c|c|c|c|c|c|c|c|c|c|c|c|}
\hline Site (N surveys/error df) & Birds & Rabbits & Possums & $\begin{array}{l}\text { Small } \\
\text { mammals }\end{array}$ & Macropods & Pigs & Echidnas & Toads & Frogs & Hopping-mice & Reptile \\
\hline Barcaldine (23/22) & $0.0589^{*}$ & $<0.0001^{*}$ & $0.0184^{*}$ & 0.2000 & 0.6600 & $0.0081^{*}$ & $0.0194^{*}$ & 0.2100 & 0.1800 & NP & RE \\
\hline Blackall (21/20) & 0.7300 & 0.5700 & $x$ & 0.5000 & $<0.0001^{*}$ & 0.7600 & 0.6800 & $x$ & 0.2400 & NP & RE \\
\hline Cordillo (7/6) & $0.0186 \wedge$ & $0.0019 \wedge$ & NP & 0.2100 & 0.6800 & 0.2500 & $x$ & NP & 0.3000 & 0.1100 & 0.1300 \\
\hline Lambina (6/5)\# & 0.2800 & 0.9000 & NP & 0.9100 & 0.5900 & NP & $x$ & $\mathrm{~Np}$ & 0.1600 & 0.6000 & 0.1300 \\
\hline Mt Owen (19/18) & $0.224 \wedge$ & $0.0002^{\wedge}$ & $<0.0001 \wedge$ & $0.0040 \wedge$ & $0.0152^{*}$ & 0.5800 & $x$ & $N R$ & $N R$ & NP & RE \\
\hline Quinyambie (14/13) & 0.8100 & $0.0493 \wedge$ & NP & 0.1200 & 0.2200 & ND & 0.6700 & NP & 0.1600 & $0.0025 \wedge$ & 0.7900 \\
\hline Strathmore (9/8) & $0.0421 \wedge$ & ND & 0.3100 & 0.1400 & $0.0001 \wedge$ & $0.0003 \wedge$ & $x$ & NR & $N R$ & NP & RE \\
\hline Tambo $(16 / 15)$ & $0.0024^{*}$ & 0.7600 & 0.3000 & 0.5400 & 0.0928 & 0.3500 & 0.3300 & 0.2200 & 0.2200 & NP & RE \\
\hline Todmorden (11/10) & 0.9100 & $0.0001^{*}$ & NP & 0.9700 & 0.4100 & NP & $x$ & NP & 0.1100 & 0.2400 & 0.0778 \\
\hline $\begin{array}{l}\text { Greater PTI in } \\
\text { Baited areas }\end{array}$ & 2 of 9 & 2 of 8 & 1 of 5 & 0 of 9 & 2 of 9 & 1 of 6 & 1 of 4 & 0 of 2 & 0 of 7 & 0 of 4 & 0 of 4 \\
\hline $\begin{array}{l}\text { Greater PTI in } \\
\text { Unbaited areas }\end{array}$ & 3 of 9 & 3 of 8 & 1 of 5 & 1 of 9 & 1 of 9 & 1 of 6 & 0 of 4 & 0 of 2 & 0 of 7 & 1 of 4 & 0 of 4 \\
\hline $\begin{array}{l}\text { Similar PTI between } \\
\text { treatment areas }\end{array}$ & 4 of 9 & 3 of 8 & 3 of 5 & 8 of 9 & 6 of 9 & 4 of 6 & 3 of 4 & 2 of 2 & 7 of 7 & 3 of 4 & 4 of 4 \\
\hline
\end{tabular}

${ }^{*}=$ Greater in baited areas; $\wedge=$ greater PTI in unbaited areas; NP = not present; ND = known to be present but not detected on tracking plots; NR $=$ present and detected but not recorded; $\mathrm{RE}=$ mostly Varanus spp. and reported in [25]; $\mathrm{X}=$ insufficient data to calculate $\mathrm{p}$; \#N surveys for hopping-mice at Lambina = 5, error $\mathrm{df}=4$ for hopping-mice.

trends in these four cases could not be related to changes in dingo PTI trends.

\section{Discussion}

Evidence for top-predator control-induced decline of prey fauna

Our results provide demonstrable experimental evidence that the prey populations we monitored are very rarely affected negatively by contemporary dingo control practices in the beef cattle rangelands of Australia. Baiting history was important only to macropods (Table 1). Overall mean prey PTI was seldom lower in baited areas than in paired unbaited areas (Tables 2 and 3). Shortterm declines in prey PTI in baited areas (relative to unbaited areas) also occurred rarely (Figure 2). Longerterm prey PTI trends fluctuated similarly in baited and unbaited areas in each case (Table 4, Figures 3, 4, 5, 6, 7, $8,9,10,11)$. Divergence or convergence of prey PTI trends was seldom observed (Figures 12, 13, 14, 15, 16, $17,18,19,20)$. These non-effects of baiting were consistent across sites and site histories, environmental contexts, and across assemblages of different grounddwelling exotic or native and small or large mammalian, avian, reptilian and amphibian prey assessed. Indeed, the few 'significant' differences observed in Steps 1, 2 or 3 of our analyses occurred infrequently and sporadically enough across sites and taxa that they may well have occurred simply by chance. If contemporary dingo control practices truly had detrimental effects on prey abundances, through either numerical and/or functional changes in predator populations, then: (1) prey PTI should have been lower in baited areas and/or (2) should have declined immediately after baiting and/or (3) should have been negatively correlated between baited and unbaited areas and/or (4) should have shown evidence of decreasing PTI trends in baited areas over time. Rarely did any of these occur for any prey species at any site, and never did our results of Step 3 show evidence of baiting-induced PTI decline for any threatened prey species or species group, such as hopping-mice or other small mammals (Figures 3, 4, 5, 6, $7,8,9,10,11,12,13,14,15,16,17,18,19,20)$.

Perhaps our best evidence of baiting-induced changes in prey populations comes from Mt Owen, where a unique combination of baiting history, baiting context, land system, mammal assemblage, rainfall and climate trend suggested that some prey species were affected by dingo control in that given context. Our experiment began at Mt Owen during a period of drought and continued through a period of repeated above-average seasonal conditions when several predator and prey species showed evidence of somewhat linear and bottom-up driven PTI increases in response to rainfall (compare Figures 7, 16 and 21 and Figure Two in [25]). This heterogeneous and structurally complex dry woodland site also supported a relatively high diversity of mammalian prey species of various sizes, including several macropod species [47-49]. The relative abundance of dingoes, cats and goannas increased in both baited and unbaited areas 
Table 3 P values obtained from repeated measures ANOVA assessing seasonal differences in mean prey PTI (surveys pooled by season) between baited and unbaited areas at nine sites across Australia

Autumn (March - May)

\begin{tabular}{|c|c|c|c|c|c|c|c|c|c|c|c|}
\hline Site ( $\mathrm{N}$ surveys/error $\mathrm{df}$ ) & Birds & Rabbits & Possums & $\begin{array}{l}\text { Small } \\
\text { mammals }\end{array}$ & Macropods & Pigs & Echidnas & Toads & Frogs & Hopping-mice & Reptile \\
\hline Barcaldine (8/7) & 0.5604 & $0.0032^{*}$ & 0.1705 & 0.2981 & 0.4162 & 0.3506 & 0.1395 & 0.1114 & 0.2718 & NP & RE \\
\hline Blackall (9/8) & 0.8598 & 0.8312 & 1.0000 & 0.5553 & $0.0336^{*}$ & 0.1690 & 0.7287 & ND & 0.4354 & NP & RE \\
\hline Cordillo $(1 / 0)$ & $x$ & $x$ & NP & $x$ & $x$ & ND & ND & ND & $x$ & $x$ & $x$ \\
\hline Lambina (1/0) & $x$ & ND & NP & $x$ & $x$ & NP & ND & NP & $x$ & $x$ & $x$ \\
\hline Mt Owen (7/6) & $0.0304 \wedge$ & 0.1624 & $0.0030^{\wedge}$ & $0.0253^{\wedge}$ & $0.0272^{*}$ & ND & ND & NR & NR & NP & RE \\
\hline Quinyambie (4/3) & 0.4972 & 0.0788 & NP & 0.2963 & 1.0000 & ND & ND & NP & 0.3910 & $0.0184 \wedge$ & 0.4444 \\
\hline Strathmore $(1 / 0)$ & $x$ & ND & $x$ & $x$ & $x$ & $x$ & ND & NR & NR & NP & RE \\
\hline Tambo (6/5) & $0.0358^{*}$ & 0.2752 & 0.6109 & 0.8215 & 0.7518 & 0.8670 & ND & 0.2586 & 0.3632 & NP & RE \\
\hline Todmorden (3/2) & 0.0785 & $0.0196^{*}$ & NP & 0.9531 & 0.6667 & NP & ND & NP & 0.4226 & 0.6892 & 0.0691 \\
\hline
\end{tabular}

Winter (June - August)

\begin{tabular}{|c|c|c|c|c|c|c|c|c|c|c|c|}
\hline Site ( $\mathrm{N}$ surveys/error $\mathrm{df}$ ) & Birds & Rabbits & Possums & $\begin{array}{l}\text { Small } \\
\text { mammals }\end{array}$ & Macropods & Pigs & Echidnas & Toads & Frogs & Hopping-mice & Reptile \\
\hline Barcaldine (6/5) & 0.1467 & $0.0089^{*}$ & 0.3144 & 0.9490 & 0.4187 & 0.2031 & 0.4206 & 0.3632 & ND & NP & RE \\
\hline Blackall (6/3) & 0.4169 & 0.8671 & $x$ & 0.3199 & $0.0045^{*}$ & 0.4918 & 0.8240 & ND & 0.3910 & NP & RE \\
\hline Cordillo $(2 / 1)$ & 0.1869 & 0.4097 & NP & 0.5529 & 0.1257 & ND & ND & ND & ND & $0.0424^{*}$ & $0.0424 \wedge$ \\
\hline Lambina (3/2)\# & 0.2747 & 0.2697 & NP & 0.3801 & 0.5093 & NP & ND & NP & 0.4226 & 0.4795 & 1.0000 \\
\hline Mt Owen (5/4) & 0.2927 & $0.0010^{\wedge}$ & $0.0433^{\wedge}$ & 0.4827 & 0.1192 & 0.3739 & ND & NR & NR & NP & RE \\
\hline Quinyambie (6/5) & 0.5071 & 0.0983 & NP & 0.4130 & 0.3278 & ND & 0.3632 & NP & ND & 0.1059 & 0.2543 \\
\hline Strathmore (6/5) & 0.0677 & ND & 0.2856 & 0.4743 & $0.0011 \wedge$ & 0.0023 & ND & NR & NR & NP & RE \\
\hline Tambo (4/3) & 0.1064 & 0.1737 & 0.3910 & 0.4564 & 0.1802 & 0.8240 & 0.3910 & ND & ND & NP & RE \\
\hline Todmorden (2/1) & 0.7863 & $0.0577^{*}$ & NP & 0.2284 & 0.1257 & NP & ND & NP & ND & 0.2048 & 0.0903 \\
\hline \multicolumn{12}{|c|}{ Spring (September - November) } \\
\hline Site ( $\mathrm{N}$ surveys/error $\mathrm{df}$ ) & Birds & Rabbits & Possums & $\begin{array}{l}\text { Small } \\
\text { mammals }\end{array}$ & Macropods & Pigs & Echidnas & Toads & Frogs & Hopping-mice & Reptile \\
\hline Barcaldine (6/5) & 0.7361 & $0.0050^{*}$ & 0.1019 & 0.2557 & 1.0000 & $0.0583^{*}$ & 0.0041 & ND & 0.3632 & NP & RE \\
\hline Blackall (6/5) & 0.8789 & $0.0578^{*}$ & ND & 0.5583 & $0.0116^{*}$ & ND & 0.8717 & ND & 0.3632 & NP & RE \\
\hline Cordillo (3/2) & 0.1428 & $0.0533 \wedge$ & NP & 0.3036 & $0.0198^{*}$ & 0.4226 & ND & ND & 0.4226 & 0.9387 & 0.4400 \\
\hline Lambina (0/0) & NS & NS & NP & NS & NS & NP & NS & NP & NS & NS & NS \\
\hline Mt Owen (6/5) & 0.1927 & $0.0405^{\wedge}$ & $0.0008^{\wedge}$ & 0.0988 & 0.5910 & 1.0000 & ND & $N R$ & NR & NP & RE \\
\hline Quinyambie (3/2) & 0.6734 & 0.9830 & NP & 0.0991 & 0.2254 & ND & 0.4226 & NP & 0.4226 & 0.1061 & 0.3399 \\
\hline Strathmore $(2 / 1)$ & 0.2952 & ND & 1.000 & 0.5000 & 0.3017 & 0.3529 & ND & NR & $N R$ & NP & RE \\
\hline Tambo (4/3) & 0.0904 & $0.0021 \wedge$ & 0.6042 & 0.0663 & 0.5720 & 0.1411 & 1.0000 & ND & ND & NP & RE \\
\hline Todmorden (2/1) & 0.0997 & 0.3375 & NP & 0.8688 & $x$ & NP & ND & NP & 0.5000 & 0.2857 & 0.1526 \\
\hline \multicolumn{12}{|c|}{ Summer (December - February) } \\
\hline Site ( $\mathrm{N}$ surveys/error $\mathrm{df}$ ) & Birds & Rabbits & Possums & $\begin{array}{l}\text { Small } \\
\text { mammals }\end{array}$ & Macropods & Pigs & Echidnas & Toads & Frogs & Hopping-mice & Reptile \\
\hline Barcaldine (3/2) & 0.1493 & 0.3249 & 0.2254 & 0.4045 & 0.3101 & 0.2254 & 1.0000 & 0.4226 & ND & NP & RE \\
\hline Blackall (2/1) & 0.5303 & 0.9097 & ND & 0.1131 & 0.2389 & 0.5000 & ND & ND & 0.5000 & NP & RE \\
\hline Cordillo $(1 / 0)$ & $x$ & $x$ & NP & $x$ & $x$ & $x$ & ND & ND & $x$ & $x$ & $x$ \\
\hline Lambina $(2 / 1)$ & 0.3712 & 0.6051 & NP & 0.7018 & 0.5000 & NP & ND & NP & 0.5000 & 0.0622 & 0.3375 \\
\hline Mt Owen (1/0) & $x$ & $x$ & $x$ & $x$ & $x$ & ND & ND & NR & NR & NP & RE \\
\hline Quinyambie (1/0) & $x$ & $x$ & NP & $x$ & ND & ND & ND & NP & ND & $x$ & $x$ \\
\hline Strathmore $(0 / 0)$ & NS & NS & NS & NS & NS & NS & NS & NS & NS & NP & NS \\
\hline
\end{tabular}


Table 3 P values obtained from repeated measures ANOVA assessing seasonal differences in mean prey PTI (surveys pooled by season) between baited and unbaited areas at nine sites across Australia (Continued)

\begin{tabular}{llllllllllll}
\hline Tambo (2/1) & 0.5718 & 0.5000 & ND & 0.5000 & 0.1772 & 0.5000 & 0.5000 & ND & 0.5000 & NP & RE \\
Todmorden (4/3) & 0.8290 & 0.0632 & NP & 0.3193 & 0.1027 & NP & ND & NP & 0.3910 & 0.8470 & $0.0021^{*}$ \\
\hline
\end{tabular}

$\mathrm{NP}=$ not present; ND = known to be present but not detected on tracking plots; NR = present and detected on tracking plots but not recorded; RE = Mostly Varanus spp. and reported in [25]; $\mathrm{X}=$ insufficient data; *All reptiles except for Varanus spp. (i.e. predominately agamidae and skincidae); $\wedge$ All dasyurids and rodents except for hopping-mice.

over the course of the study there (Table 5, and Figure Two in [25]), and were numerically unaffected by baiting (Figures 7 and 16). In this context, however, macropods and rabbits (Oryctolagus cuniculus) increased in the baited area where possums (Trichosurus vulpecula) decreased (Figures 7 and 16); all other taxa showed no evidence of baiting-induced changes in PTI trends. Possums (53\% occurrence), macropods (29\% occurrence) and rabbits (7\% occurrence) were the three most frequently occurring prey species in dingo diets at Mt Owen, where dingoes switched seasonally between macropods and possums $[47,48]$. These observations suggest that baiting-induced changes to dingo populations can occur in some contexts, whereby large macropod prey can become unavailable (or uncatchable) to socially-fractured dingo populations exposed to baiting, which then must switch to alternative prey more easily captured $[47,50]$. In this case, dingoes exposed to baiting appeared to suppress populations of common possums, but not any other more threatened small mammal species. The historical decline of possums in the Australian rangelands has previously been attributed to dingo predation [51-53]. Whether or not these baitinginduced prey responses are sustained subsequent to a change in the ecological context is unknown, but unlikely, given that baiting-induced functional changes in dingo movement behaviour [54] or prey selection (B. Allen, unpublished data from $[55,56]$ ) did not occur at several other sites where these processes were investigated (Table 4, Figures 3, 4, 5, 6, 8, 9, 10, 11, 12, 13, 14, 15 and $17,18,19,20)$. These variable results suggest that the few numerical changes we observed in some of the preferred dingo prey species at some sites may be related to context-specific functional changes to dingo populations subjected to baiting, which might sometimes occur.

Although patterns in prey PTI were typically unaffected by dingo control, it is possible that prey behaviour might have been altered - perhaps negatively - through changes to the landscape of fear $[12,57,58]$. In other words, baiting-induced changes to dingo function (if or when it occurs) might allow mesopredators to forage more freely and then increase predation pressure on prey, negatively affecting prey behaviour and fitness $[32,33,59]$. Changes to the landscape of fear might occur independently of numerical trends in predator populations. Step 2 of our analyses provided the greatest opportunity to assess the behavioural responses of prey to predator control, yet short-term changes in prey PTI were not apparent in most

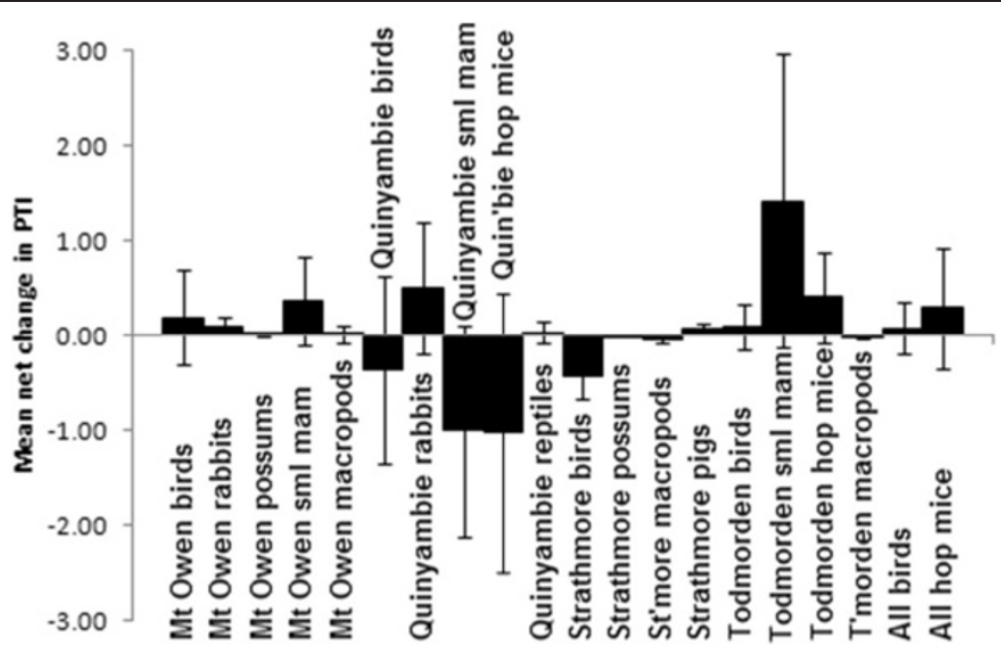

Figure 2 Mean net changes in prey PTI (and 95\% confidence intervals) between pre- and post-baiting surveys (conducted within four months of baiting) at Mt Owen $(N=8)$, Quinyambie $(N=4)$, Strathmore $(N=5)$, Todmorden $(N=5)$ and all sites combined $(N=25)$, showing little evidence of short-term decreases in prey PTI following dingo control. 
Table 4 Correlations ( $r$ ) and $p$ values $(p)$ for relationships in longer-term prey PTI trends between baited and unbaited areas at nine sites across Australia

\begin{tabular}{|c|c|c|c|c|c|c|c|c|c|c|c|c|}
\hline Site & & Birds & Rabbits & Possums & Small mammals^ & Macropods & Pigs & Echidnas & Toads & Frogs & Hopping-mice & Reptiles* \\
\hline \multirow{2}{*}{ Barcaldine } & $r$ & 0.7770 & 0.8134 & 0.0461 & 0.8427 & 0.8297 & 0.1693 & -0.0767 & -0.0878 & 0.6114 & \multirow{2}{*}{ NP } & \multirow{2}{*}{ RE } \\
\hline & $p$ & $<0.0000$ & $<0.0000$ & 0.8346 & $<0.0000$ & $<0.0000$ & 0.4399 & 0.7280 & 0.6905 & 0.0019 & & \\
\hline \multirow{2}{*}{ Blackall } & r & 0.5024 & 0.1790 & -0.0500 & 0.5191 & 0.7382 & -0.1062 & 0.3442 & \multirow{2}{*}{ ND } & -0.0670 & \multirow{2}{*}{ NP } & \multirow{2}{*}{ RE } \\
\hline & $p$ & 0.0203 & 0.4376 & 0.8296 & 0.0159 & 0.0001 & 0.6469 & 0.1266 & & 0.7730 & & \\
\hline \multirow{2}{*}{ Cordillo } & r & 0.4135 & 0.4077 & \multirow{2}{*}{ NP } & 0.9100 & 0.3372 & \multirow{2}{*}{$X$} & \multirow{2}{*}{ ND } & \multirow{2}{*}{ NP } & \multirow{2}{*}{$X$} & 0.0893 & 0.3938 \\
\hline & $\mathrm{p}$ & 0.3564 & 0.3640 & & 0.0044 & 0.4595 & & & & & 0.8489 & 0.3755 \\
\hline \multirow{2}{*}{ Lambina } & $r$ & 0.8835 & 0.7018 & \multirow{2}{*}{ NP } & 0.9568 & 0.8849 & \multirow{2}{*}{ NP } & \multirow{2}{*}{ ND } & \multirow{2}{*}{ NP } & 0.9931 & 0.9180 & 0.9618 \\
\hline & $p$ & 0.0196 & 0.1201 & & 0.0028 & 0.0191 & & & & 0.0001 & 0.0278 & 0.0022 \\
\hline \multirow{2}{*}{ Mt Owen } & $r$ & 0.8323 & 0.0330 & 0.6828 & 0.9017 & 0.7906 & -0.0808 & \multirow{2}{*}{$x$} & \multirow{2}{*}{ NR } & \multirow{2}{*}{ NR } & \multirow{2}{*}{$N P$} & \multirow{2}{*}{$\mathrm{RE}$} \\
\hline & $p$ & $<0.0000$ & 0.8932 & 0.0013 & $<0.0000$ & 0.0001 & 0.7421 & & & & & \\
\hline \multirow{2}{*}{ Quinyambie } & $r$ & 0.4265 & 0.8052 & \multirow{2}{*}{ NP } & 0.9834 & -0.1040 & ND & -0.0769 & \multirow{2}{*}{ NP } & \multirow{2}{*}{$x$} & 0.9557 & 0.7755 \\
\hline & $p$ & 0.1283 & 0.0005 & & $<0.0000$ & 0.7235 & & 0.7938 & & & $<0.0000$ & 0.0011 \\
\hline \multirow{2}{*}{ Strathmore } & $r$ & 0.8764 & ND & 0.5093 & 0.2370 & 0.7563 & 0.8764 & \multirow{2}{*}{$x$} & \multirow{2}{*}{ NR } & \multirow{2}{*}{$N R$} & \multirow[t]{2}{*}{ NP } & RE \\
\hline & $p$ & 0.0019 & & 0.1613 & 0.5392 & 0.0184 & 0.0019 & & & & & \\
\hline & $r$ & 0.6343 & 0.4928 & 0.1108 & 0.8318 & 0.4171 & -0.1936 & -1215 & $x$ & 0.9932 & R & 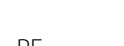 \\
\hline . & $p$ & 0.0083 & 0.0524 & 0.6829 & 0.0001 & 0.1080 & 0.4726 & 0.6539 & $x$ & $<0.0000$ & TNr & $\mathrm{nL}$ \\
\hline Ten & $r$ & 0.7226 & -0.0273 & $N P$ & 0.8860 & 0.8865 & $N P$ & (م) & $A P$ & $x$ & 0.7589 & 0.1210 \\
\hline 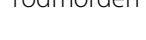 & $p$ & 0.0120 & 0.9365 & $\mathrm{TN}$ & 0.0003 & 0.8865 & $\mathrm{TVI}$ & TVD & ivr & $\lambda$ & 0.0068 & 0.7231 \\
\hline
\end{tabular}

$\mathrm{NP}=$ not present; $\mathrm{X}=$ insufficient data; Goannas represent only Varanus spp. at Cordillo, Lambina, Quinyambie and Todmorden, but include a small proportion of other reptiles at the other sites (see also [25]).

cases (Figure 2). Comprehensive reviews of the short-term effects of dingo control on prey concur with our results to show that populations of non-target prey are not negatively affected by dingo control $[60,61]$. Specifically investigating the behavioural responses of prey to dingo control, Fenner et al. [62] likewise found no change in small mammal prey behaviour following baiting. The predator manipulation experiments conducted by Eldridge et al. [39] similarly show prey populations (such as birds and reptiles) to fluctuate independent of dingo control. Modelling the outcomes of dingo reintroduction and cessation of fox control on prey fauna in forested temperate areas by Dexter et al. [63] also suggests small mammal populations fluctuate largely independent of dingoes. Whereas, the predator exclosure experiments of Kennedy et al. [64] suggest that some small mammal prey of dingoes benefit from dingo exclusion, as predicted by Allen and Leung [55]. The predator exclosure experiment of Moseby et al. [65] showed that some rodents benefited from the removal of rabbits, dingoes and other predators, whereas reptiles, dasyurids and other rodents were largely unaffected by their exclusion. If baiting-induced behaviourally-mediated trophic cascades were occurring at our sites, such changes were not manifest as numerical effects on longer-term prey abundance trends in most cases (Tables 1, 2 and 3, Figures 3, 4, 5, 6, 7, 8, 9, 10, 11).
These results contradict perceptions (reviewed in [35,36]) that (1) prey population abundances are lower in baited areas, (2) prey activity is suppressed shortly after baiting, (3) commencement of baiting produces declines in prey abundances, and (4) cessation of baiting increases prey abundances. Long-term (10-28 years) correlative studies of dingoes, mesopredators and their prey concur with these experimental results (e.g. $[37,38]$ ), and "almost all available studies reporting dissimilar results are based on demonstrably confounded predator population sampling methods and/or low-inferential value study designs that simply do not have the capacity to provide reliable evidence for dingo control-induced mesopredator release" ([40], pg. 4). Thus, not only is there a clear absence of reliable evidence for dingo controlinduced trophic cascades (e.g. [46,66]), but there is also a strong and growing body of demonstrable experimental evidence that prey populations are usually affected positively (not negatively) by dingo control if prey are affected at all (e.g. [55,59], this study).

\section{Trophic cascade and mesopredator release theory and reality}

Trophic cascade and mesopredator release theory predicts that declines of top-predators produce increases of mesopredators and larger herbivores, which then 


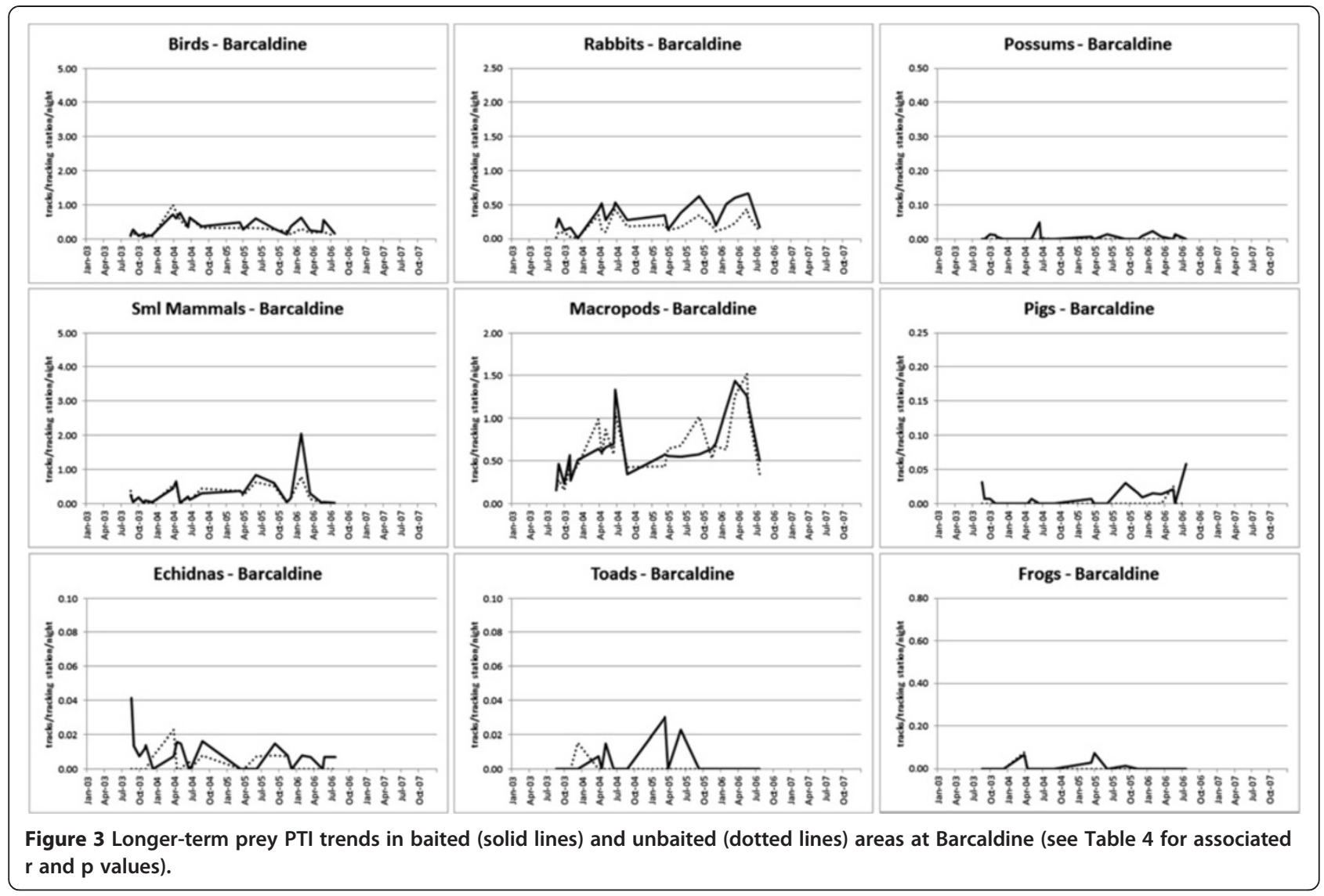

produce declines in smaller prey, which are often threatened $[5,7]$. The theory appears to work best in reality when food webs are simpler and less complex $[67,68]$. Deriving their conclusions from desktop studies, snapshot field studies and/or those conducted on fauna on other continents, some have predicted that dingo control will release feral pigs (Sus scrofa), macropods and rabbits from dingo suppression, which will then simultaneously reduce the abundances of hopping-mice and other small mammals, birds and other fauna [13,36,69]. Thus, toppredator management programs that kill, remove or alter the function of top-predators might conceivably produce indirect declines of threatened fauna $[8,34]$. Despite the potential for substantial and direct negative effects of dingoes on the same threatened fauna through predation $[26,51,55,70]$, such predictions have led some to advocate cessation of dingo control programs with the expectation that doing so will provide widespread net benefits to threatened fauna at lower trophic levels (e.g. $[13,32,71])$. However, our simultaneous assessment of the effects of dingo control on predator and prey populations demonstrated that the predicted mesopredator increases do not occur (Table 5 and Figures 12, 13, 14, $15,16,17,18,19,20$; see also Figure Two in [25]) because contemporary dingo control practices "do not appear to suppress dingo populations to levels low enough and long enough for mesopredators to exploit the situation" ([25], pg. 11). Hence, the consistent absences of negative prey responses to dingo control we found (Tables 1, 2 and 3, Figures 2, 3, 4, 5, 6, 7, 8, 9, 10, $11,12,13,14,15,16,17,18,19,20)$ should be entirely expected given that the prerequisite first step or trigger for the predicted trophic cascade (i.e. dingo decline) did not occur (Figures 12, 13, 14, 15, 16, 17, 18, 19, 20). Whatever the relationships between dingoes and mesopredators or prey are, they do not appear to be affected by contemporary dingo control practices to any substantial degree. Alternative dingo control strategies which actually achieve sustained reduction of dingo abundances and/or alteration of dingo function may produce different results that might lend support to popular predictions of dingo controlinduced trophic cascades or mesopredator release [25].

Although the occurrence of trophic cascades is well demonstrated $[7,8]$, whether or not they are caused by top-predators or top-predator control is far less certain $[46,72,73]$ and undoubtedly context-specific. For example, results of studies conducted on big cats, bears or wolves in temperate mountainous areas with diverse mammal 


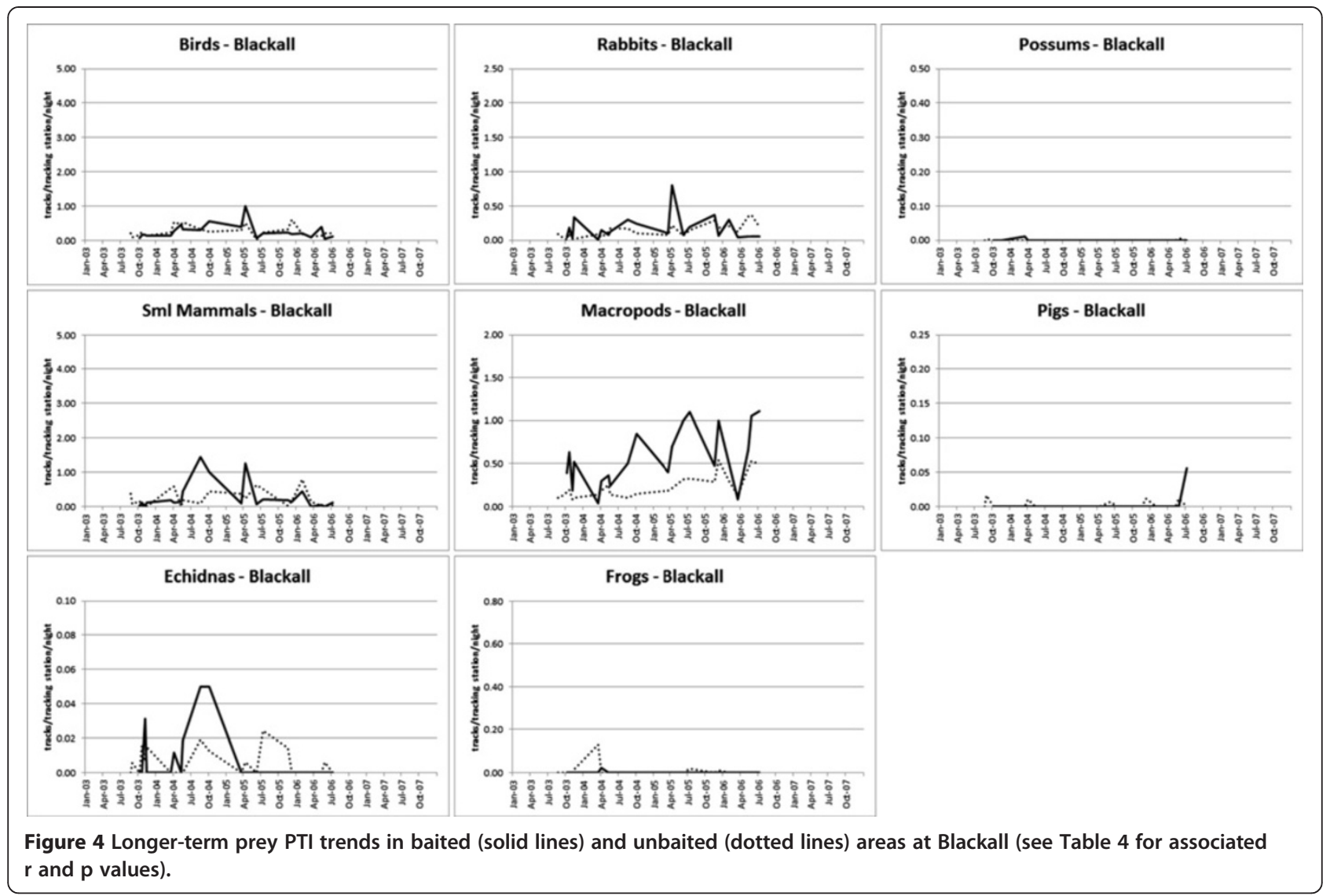

assemblages largely untouched by humans are not easily transferable to other predators occupying the severely human-altered areas that dominate the earth's surface [18], such as dingoes and the relatively depauperate mammal assemblages in the beef cattle rangelands of Australia [19]. Moreover, by undertaking applied-science experiments which circumvent investigations of the internal processes at play and instead focus on the actual in situ prey responses to top-predator control (R6 in Figure 1) - what Kinnear et al. [74] label the 'black box' approach - our results confirm that prey populations are typically unaffected by contemporary dingo control practices independent of how predators and prey might interact with each other (R2 in Figure 1).

Our findings are in accord with what is known from other predator manipulation experiments worldwide. Fauna at lower trophic levels are unlikely to respond positively to lethal control where (1) multiple predators are removed (i.e. dingoes and foxes are both susceptible to and targeted by baiting [25]) (2) the efficacy of predator removal is low (i.e. where predator populations are resilient to lethal control over time, as in Table 5 or Figures 12, $13,14,15,16,17,18,19,20$; see also [30] or Figure Two in [25]), and/or where (3) the fauna are not the primary prey species of the predator ([43]; but see $[48,55]$ for information on dingo diets at our sites). Though small and medium-sized mammals (such as rodents, possums and rabbits) are preferred prey for dingoes and other mesopredators alike when available $[26,55]$, fluctuations in the availability of a variety of prey species typically mean that suppression of a given prey species is often only temporary $[41,75,76]$. Besides targeting multiple predators and producing no lasting changes in predator PTI trends in our experiments (Table 5, Figures 12, 13, 14, 15, 16, 17, 18, 19, 20), the flexible and generalist nature of dingoes', foxes', cats' and goannas' prey preferences may be another reason why we did not detect changes in prey PTI trends following predator baiting.

\section{Factors affecting prey responses to predator control}

A large array of factors can influence the outcomes of predator control on prey populations [41,44,77]. The number and type of intraguild predators present, the variety and abundance of available prey, the environmental context in which predator control is undertaken, the responses and resilience of predators to that control, the dietary preferences and habits of predators, and the 


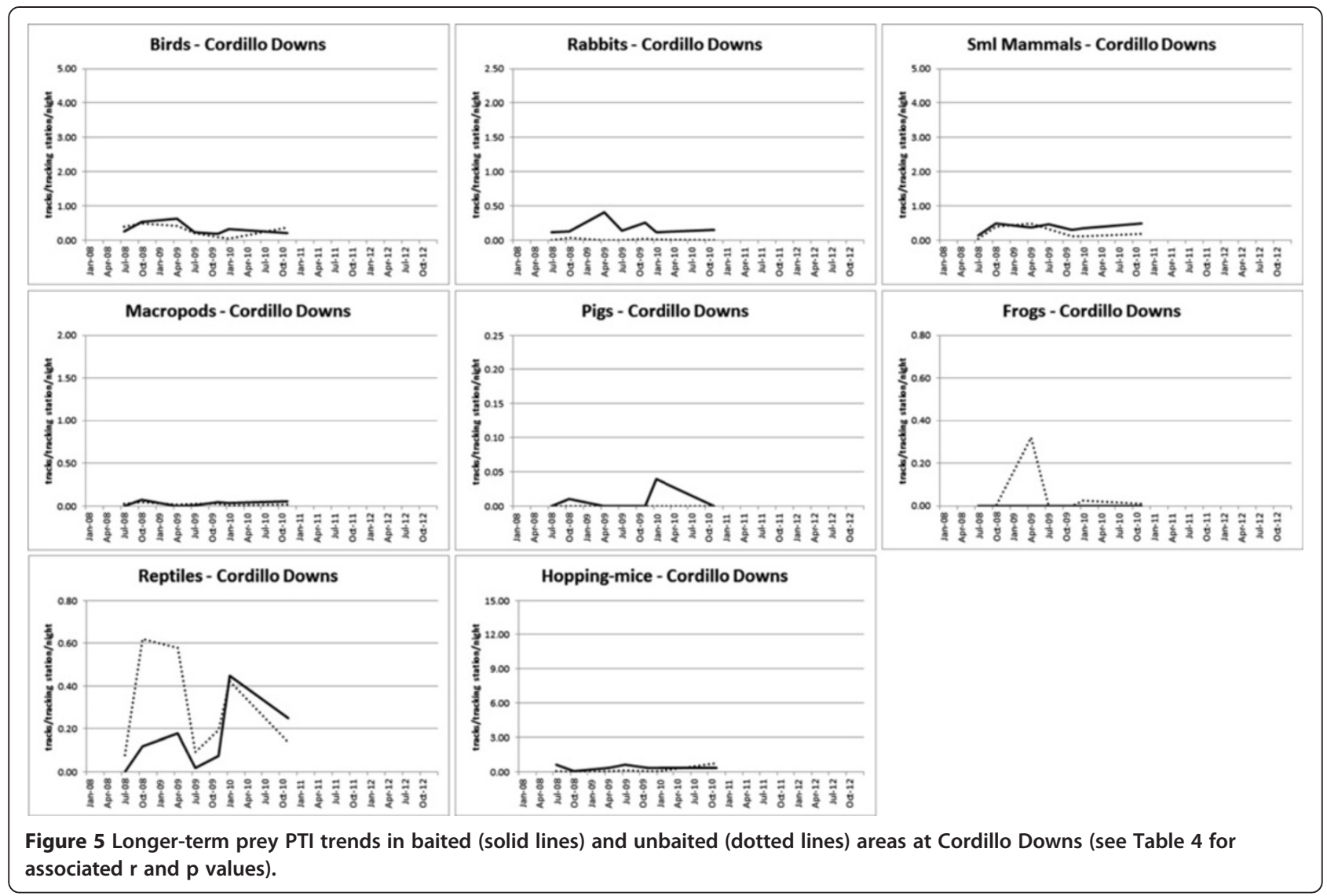

resilience of prey to changes in predator numbers or behaviour are each important factors influencing the responses of prey to predator control [41-43]. Study design and analytical approach also influences the observed outcomes given that 'what you see depends on how you look' (e.g. $[40,44,46,56])$. Changes in prey abundances following predator control might only be expected where or when predation is actually the limiting factor for prey [51,69]. Many of Australia's threatened fauna are affected to a greater degree by much more than just predator effects $[3,70,78-80]$, suggesting that alteration of predator communities or predator control strategies - in isolation of other, more important drivers of prey decline - might not be universally expected to enhance prey recovery $[14,51]$.

The timeframe over which prey are monitored may also influence the observed prey responses to predator baiting. Snap-shot studies with a single observation conducted at only $\mathrm{T}_{0}$ (e.g. [81-84]) obviously have no capacity whatsoever to measure a spatial or temporal 'change', 'shift' or 'response' to dingo control $[44,45]$, which is why we conducted multiple surveys over multiple successive years at each site $\left(T_{0}, T_{1}, T_{2} \ldots\right.$ up to $T_{23}$; Table 2). Despite conducting our experiments over these timeframes, similar to most other predator manipulation experiments [43], it is possible that $2-5$ years of repeated prey surveys might not be long enough to detect changes in prey abundances following predator removal [65]. However, three lines of evidence suggest that this is not the case for our data.

First, the PTI methodology we applied was sufficient to detect the immediate and longer-term responses of prey (and predators) to the bottom-up effects of rainfall within the timeframe covered (Figures 3, 4, 5, 6, 7, 8, 9, $10,11,12,13,14,15,16,17,18,19,20,21$; see also $[47,85])$. Some claim that the top-down effects of dingo control can be stronger than the bottom-up effects of rainfall in the systems we studied [13], so such predicted negative responses of prey to baiting should have been observable. Second, prey responses to dingo control are almost always investigated using observational snap-shot studies or correlative studies of $<12$ mo duration $[46,86]$, implying that 2-5 years of repeated baiting and population monitoring across spatial scales several orders of magnitude larger should have readily detected both acute and chronic prey declines. Third, prey population trends fluctuated similarly between treatments at Barcaldine, Blackall and Tambo (Table 4, Figures 3, 4, 5, 6, 7, $8,9,10,11,12,13,14,15,16,17,18,19,20)$ where 


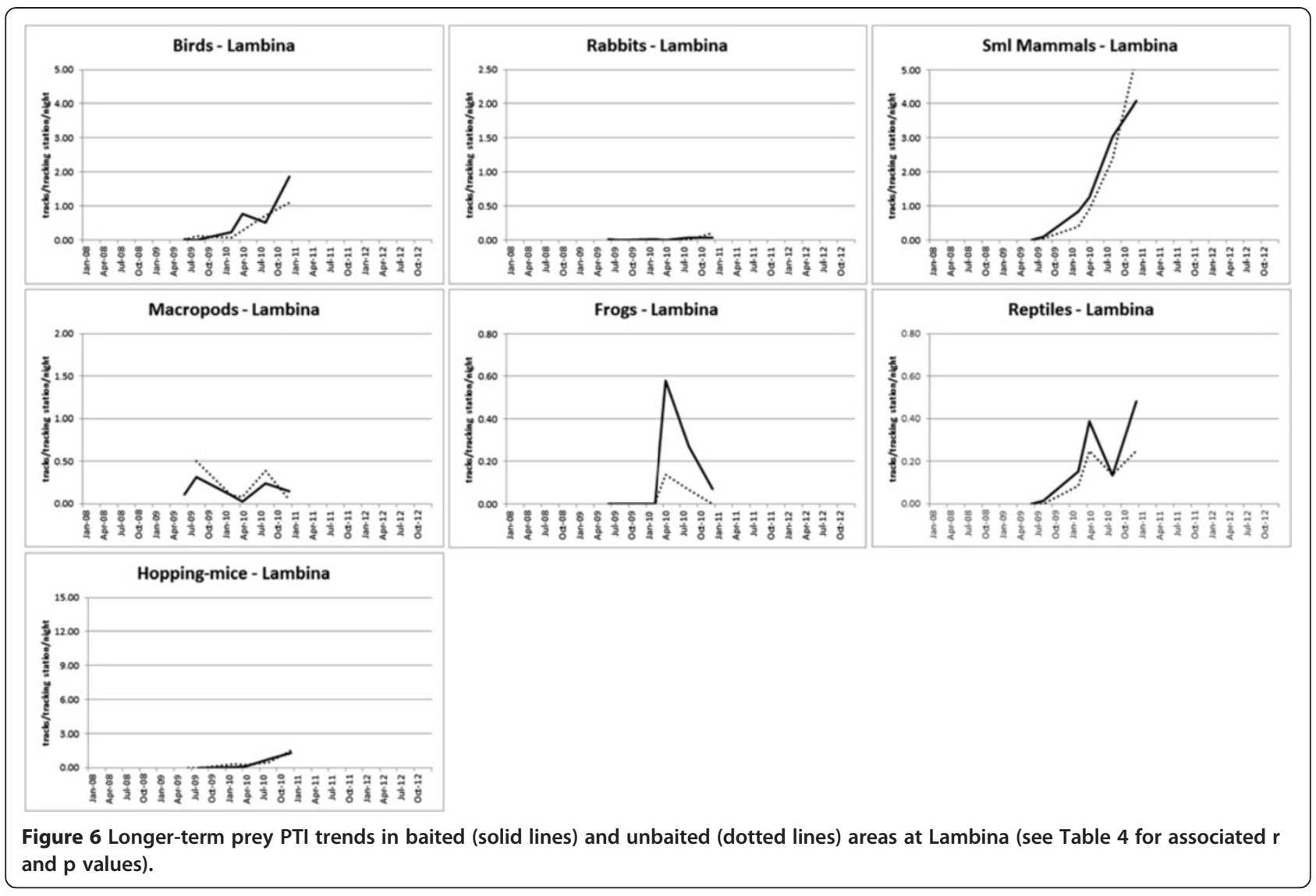

baiting had occurred multiple times each year for over 10 years [25]. Viewed in isolation, this latter result might be interpreted to suggest that prey had already declined in baited areas and was now being held below their carrying capacity; however, shorter-term declines were not apparent (Table 4, Figures 3, 4, 5, 6, 7, 8, 9, 10, 11), baiting history was not important to most species (Table 1), overall mean prey PTI was not lower in baited areas for any prey at any of the three Blackall sites (Table 2), and nor were predator PTI trends altered by baiting at these sites

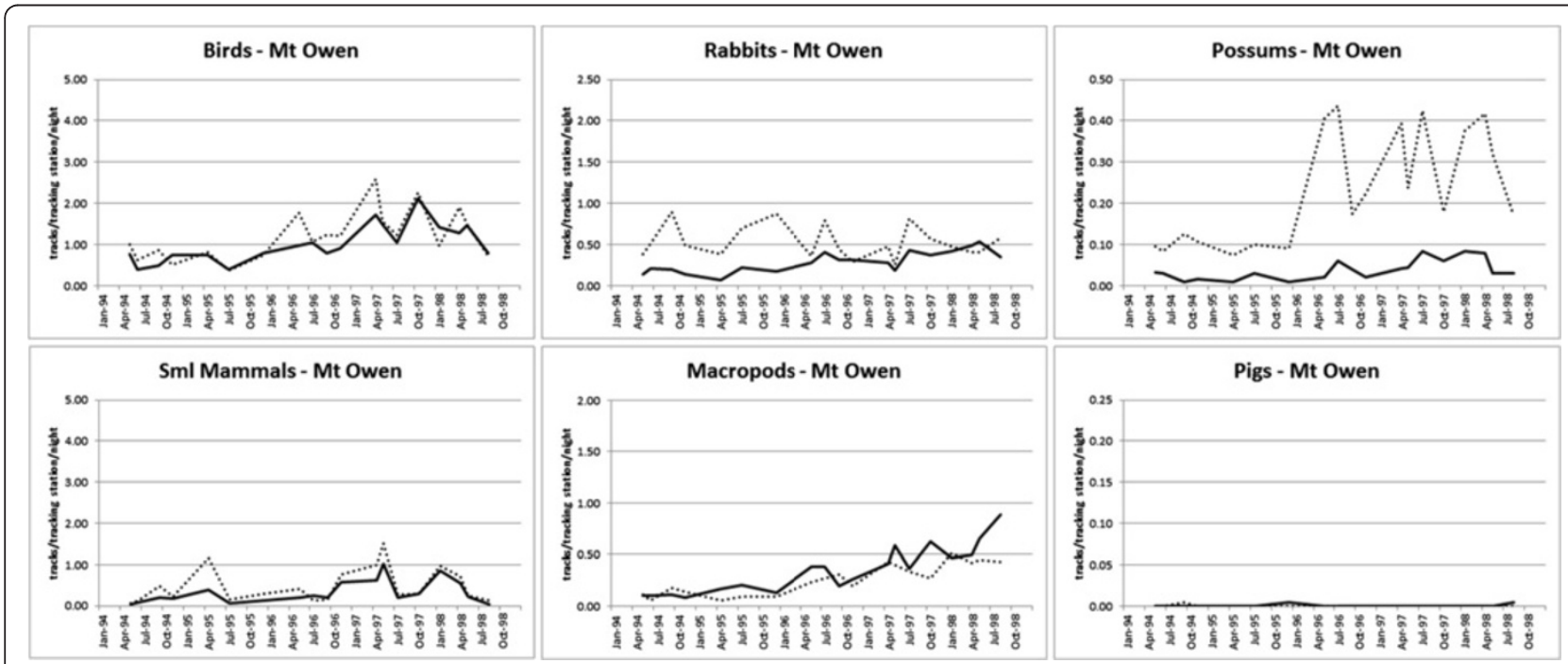

Figure 7 Longer-term prey PTI trends in baited (solid lines) and unbaited (dotted lines) areas at Mt Owen (see Table 4 for associated $r$ and $p$ values). 


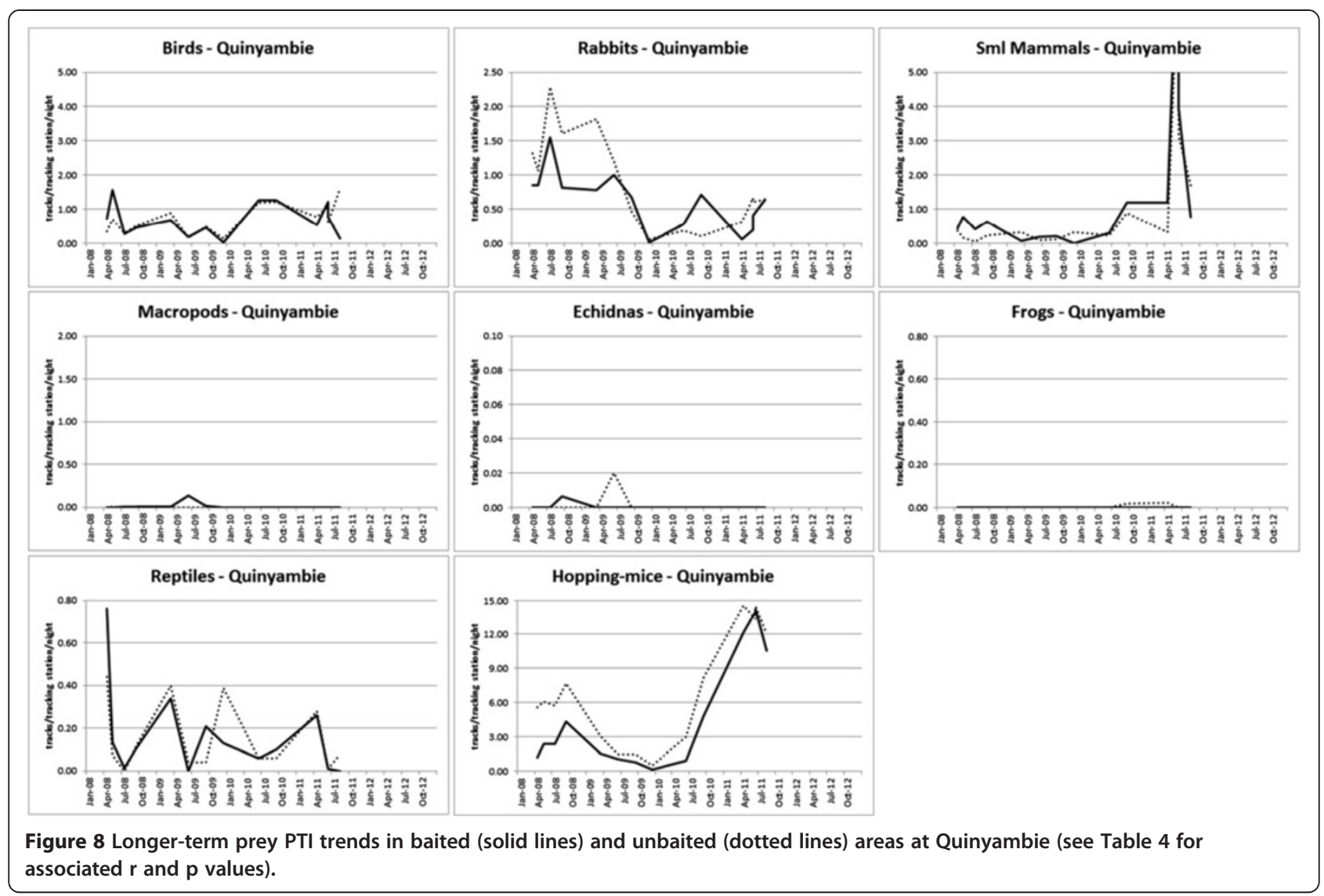

either (Table 5, Figures 12, 13, 14, 15, 16, 17, 18, 19, 20, and Figure Two in [25]). These lines of evidence indicate that our experimental design was sufficient for detecting baiting-induced changes in prey PTI if they were occurring [44].
The utility of our fauna sampling method (i.e. roadbased sand plots) is also likely to vary between species and species groups $[87,88]$. This may be one reason why the number of tracks observed, and hence PTI values, for some species were low on occasion (Table 6; see also

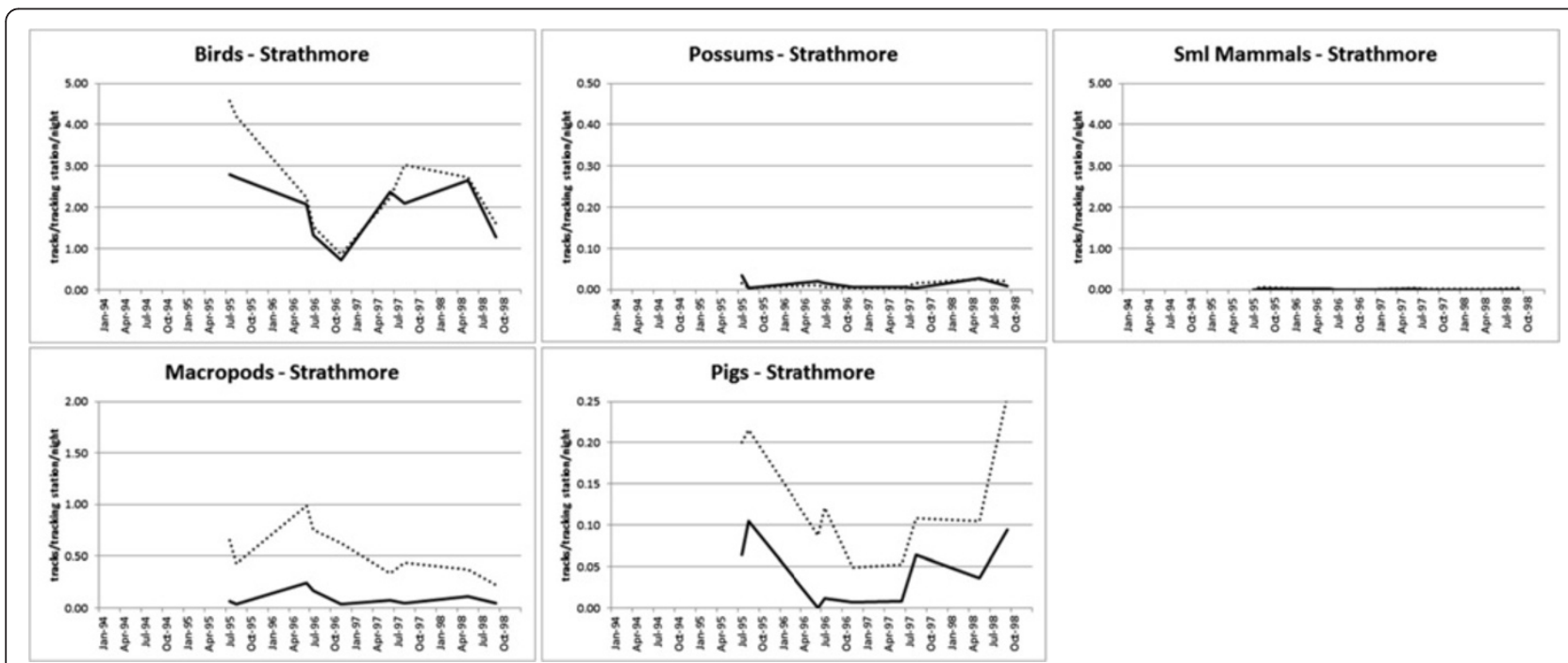

Figure 9 Longer-term prey PTI trends in baited (solid lines) and unbaited (dotted lines) areas at Strathmore (see Table 4 for associated $r$ and $p$ values). 


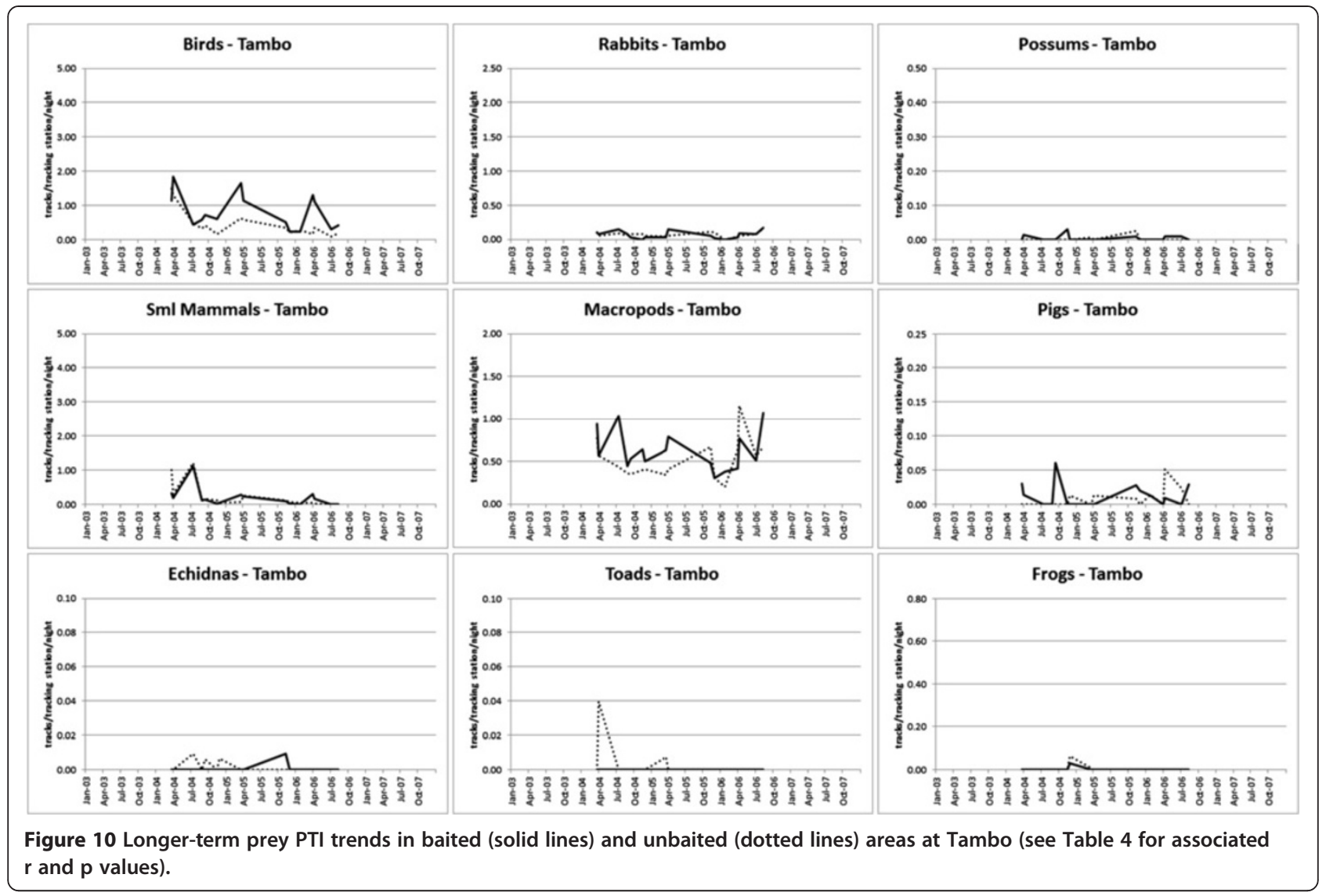

Table Six in [25]) and why their analyses yielded no significant responses to baiting (Tables 1, 2, 3, 4 and 5). However, the variable utility of the technique for different species is also of little consequence to our overall conclusions. Far from being a weakness of our study, the observance of few footprints for some species at times (confirming their presence at the study sites) is itself a key result supporting our conclusions given that the number of observations (or PTI values) did not change substantially over time in response to dingo baiting (Figures 3, 4, 5, 6, 7, 8, 9, 10, 11, 12, 13, 14, 15, 16, 17, $18,19,20$; see also [89]). Our expectation was that if baiting-induced mesopredator releases or prey suppression was occurring (see Predicted outcomes, below), then these responses should have been detectable on the 92-166 sand plots interspersed throughout the treatment areas on dirt roads at each site (Note: 'roads' here are simply the two 4WD vehicle wheel tracks that wind throughout the study sites with negligible disturbance or alteration to the extant habitat). To argue that our sampling methodology was unable to detect changes in fauna PTI is to imply that mesopredator releases or prey suppression was occurring elsewhere, or that observed predator-prey interactions were somehow different on and off the road. This is unlikely given that the activity of almost all the prey species we monitored (e.g. macropods, rabbits, small mammals, birds, reptiles etc.) occurs randomly with respect to roads at our sites, unlike the mammalian predators whose behaviour is influenced by roads [90,91]. Moreover, supplementary studies indicated that baiting did not affect dingo movement behaviour, which was similar both on and off the road just prior and subsequent to baiting [54]. Sampling fauna populations by placing tracking plots on roads is by no means 'insensitive' or of little value just because the approach may produce lower PTI values for some species relative to other tracking plot placements or sampling approaches, providing fauna populations are not below the level of detection by the method. Although some species (e.g. cats, small mammals or reptiles) may have persisted below the level of detectability on roads under certain conditions (e.g. during drought for small mammals or during winter for reptiles), such species were readily detected again on roads when these conditions changed (compare Figures 3, 4, 5, 6, 7, 8, 9, 10, 11 and 21; see also [47]). Thus, Step 3 in our analytical approach (Figures 3, 4, 5, 6, 7, 8, 9, 10, 11, 12, 


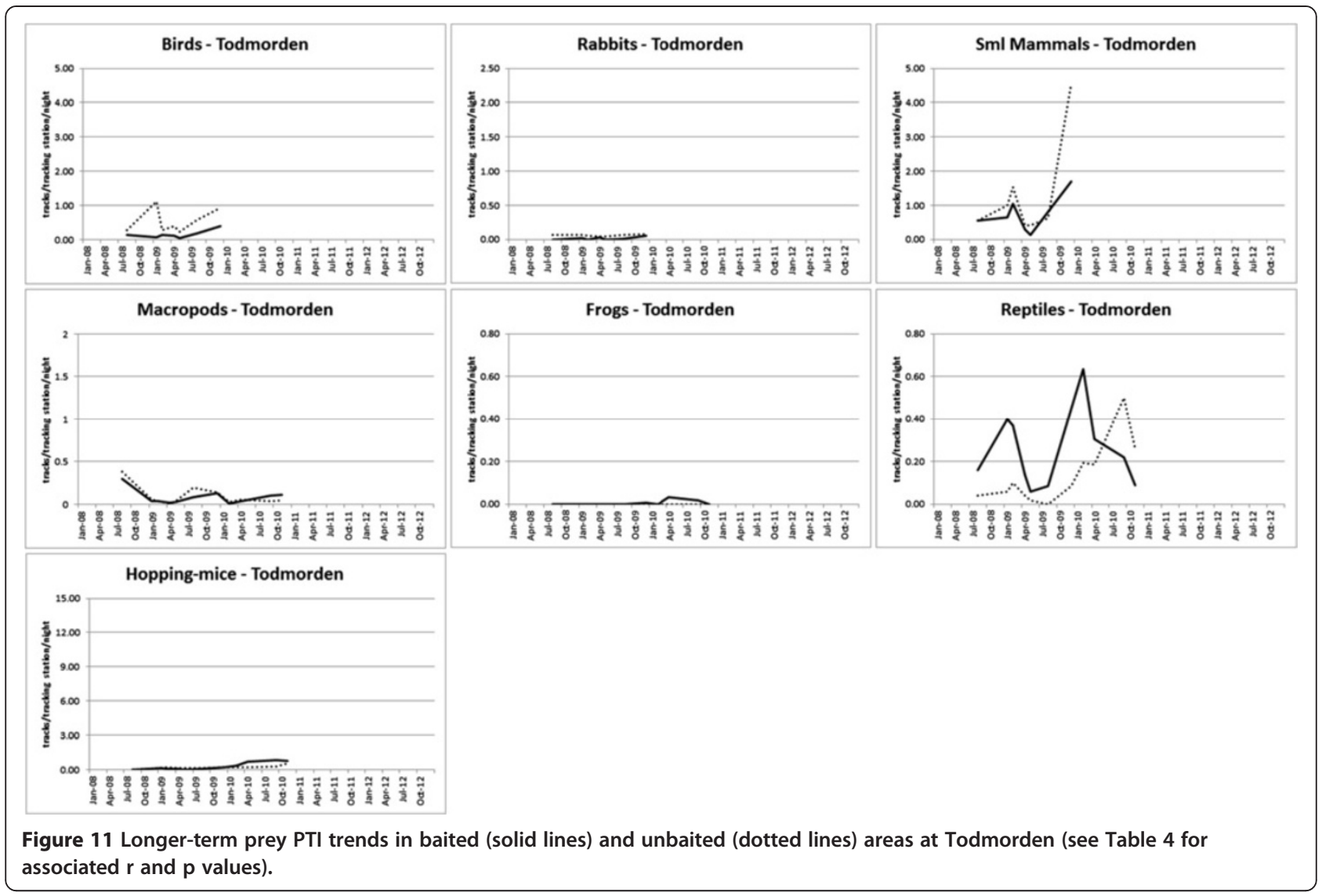

$13,14,15,16,17,18,19,20)$ should have detected predator and prey PTI responses to baiting if they were occurring, regardless of the variable utility of road-based tracking plots for different species.

Although we undertook our study in an experimental framework inclusive of buffer zones to maximise treatment independence, it is also important to remember that our approach was an evaluation of the overall population-level responses of prey to contemporary toppredator control practices under real-world environmental conditions where predators and prey were each capable of dispersal and migration between treatments over time. In other words, we sought not to compare niltreatment areas to paired treated areas with ' $\mathrm{X} \%$ reduction of predators' or 'X density of baits', but with 'contemporary dingo control practices'. This applied-science focus therefore produces results that reflect the in situ outcomes of contemporary dingo control practices in the beef-cattle rangelands present across much of the Australian continent. Dingo control strategies that actually achieve complete and sustained dingo removal from the landscape (such as those that include exclusion fencing and eradication) may produce different results, though such strategies are unlikely to ever occur in the $>5.5$ million $\mathrm{km}^{2}$ (or $\sim 75 \%$ ) of Australia where sheep (Ovis aries) and goats (Capra hircus) are not commercially farmed [27].

\section{Conclusions and implications}

Our results add to the growing body of experimental evidence that prey populations in rangeland Australia are not negatively affected by contemporary dingo control practices through trophic cascade effects. These findings broaden our understanding of the potential outcomes of predator control on prey fauna at lower trophic levels and have important implications for the management of dingoes and threatened fauna. Given the ineffectiveness of contemporary baiting practices at sustainably reducing dingo populations, it might be concluded that dingo control is a pointless waste of time, money and dingoes, which may even be counterproductive to cattle producers at times [50,92]. Importantly however, dingo control is typically undertaken to reduce or avert damage to livestock by dingoes, not to reduce dingo densities per se, and the relationship between dingo density and damage is not well understood 


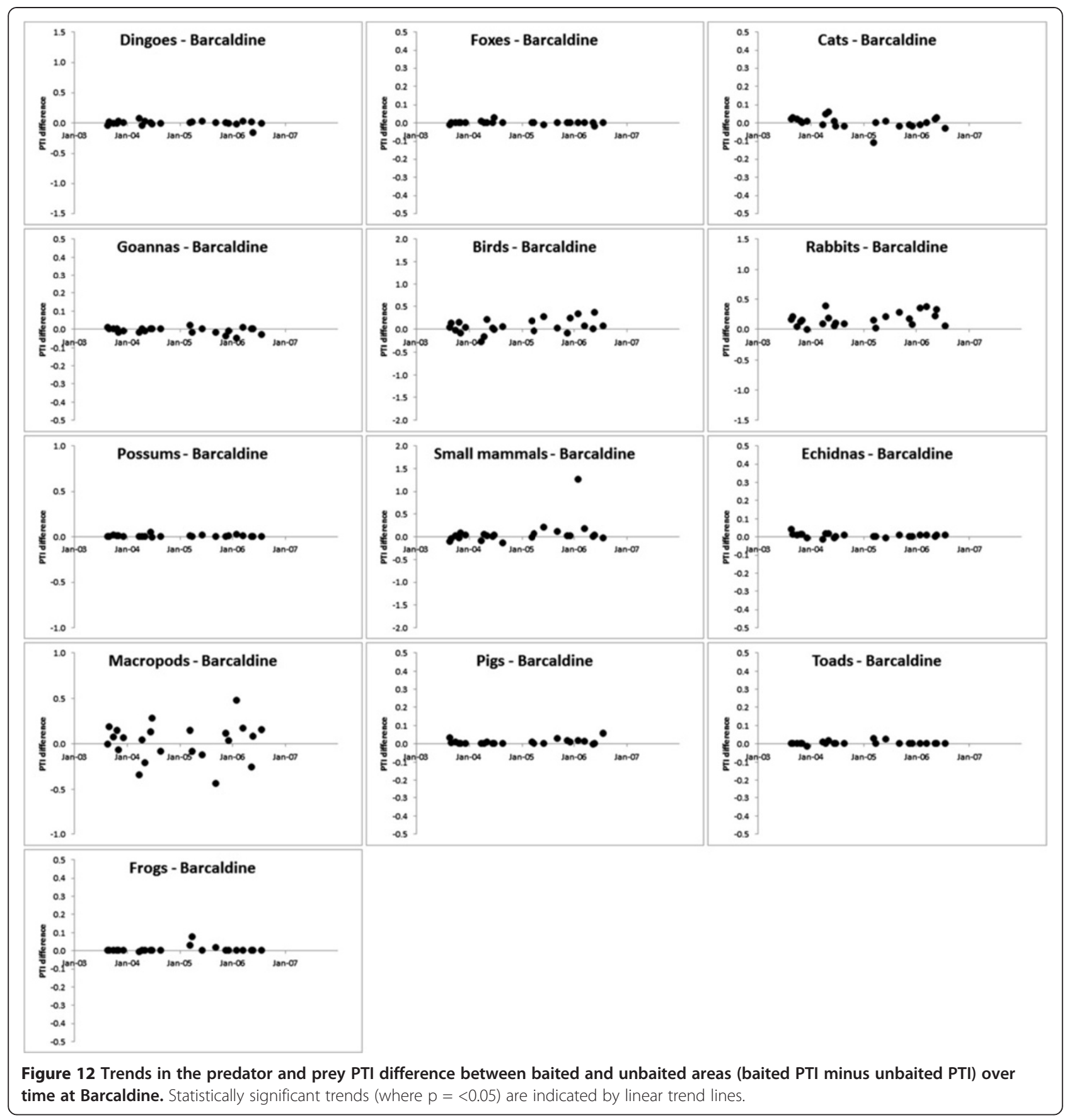

[31,93]. Hence, the 'effectiveness' of dingo control should ultimately be measured in terms of 'damage reduced' or 'losses averted', not in terms of '\% reduction in dingo PTI', '\% dingoes destroyed', '\% people participating in dingo control', or the '\% of land area exposed to control' [44,94]. Greater emphasis on measurable damage reduction and/ or mitigation appears warranted in order to ethically justify continued dingo control programs.
Some have also theorised that simply ceasing lethal dingo control is a 'free' or cost-effective strategy able to increase the abundances of threatened prey fauna populations of conservation concern through trophic cascade effects (e.g. $[13,32,34,95,96])$, but our results demonstrate that such actions do not produce such outcomes. Fauna recovery programs should more carefully consider the factors limiting threatened prey populations 


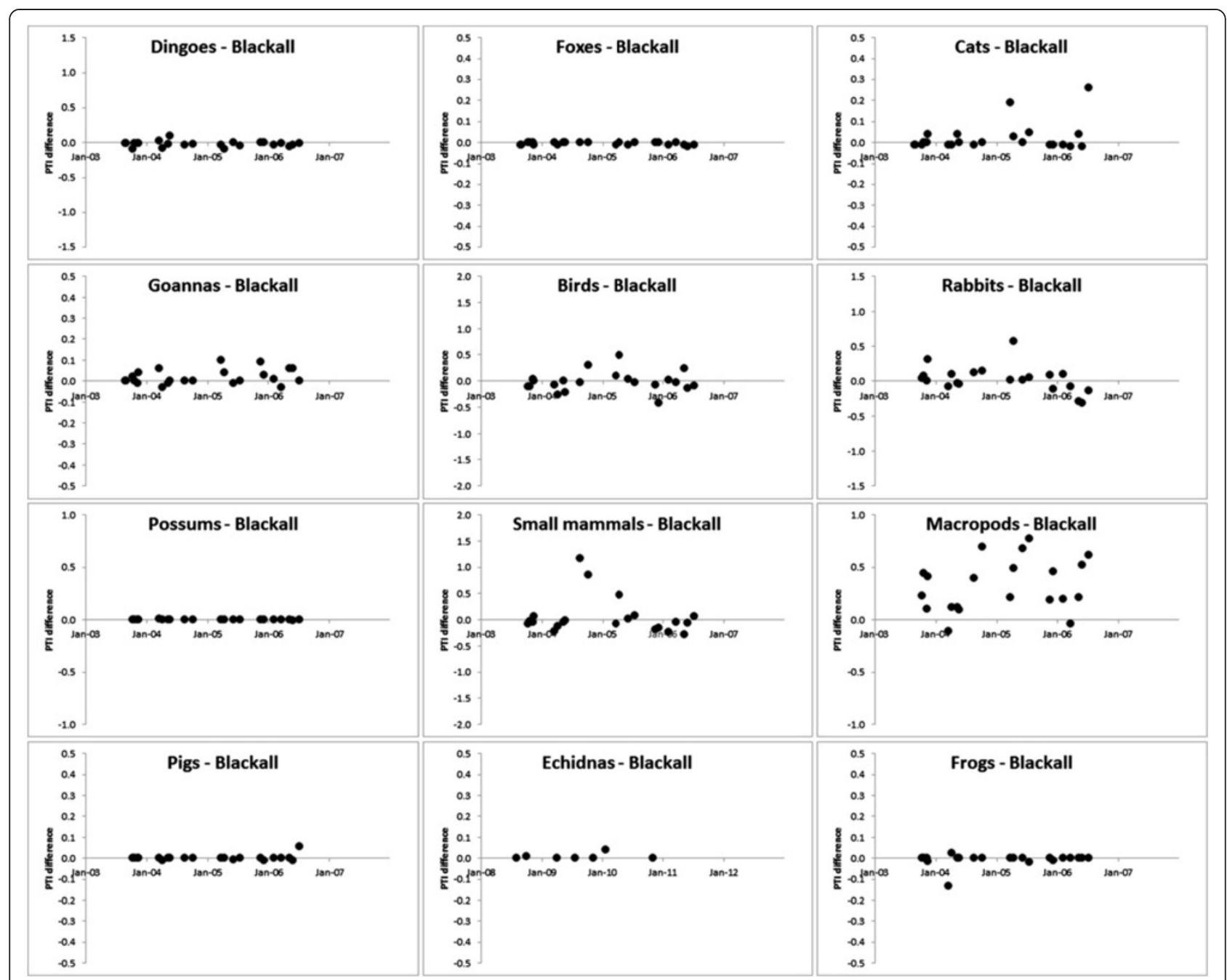

Figure 13 Trends in the predator and prey PTI difference between baited and unbaited areas (baited PTI minus unbaited PTI) over time at Blackall. Statistically significant trends (where $p=<0.05$ ) are indicated by linear trend lines.

of interest and the general indifference of predator and prey populations to contemporary dingo control practices before altering current predator control strategies. We conclude, as have others (e.g. $[14,59,97])$, that proposals to cease dingo control are presently unjustified on grounds that contemporary dingo control somehow harms prey fauna through trophic cascade effects. Our experimental results should be valuable for informing dingo and threatened fauna management plans given that "the majority of work to date has been largely observational and correlative" ([98], pg. 64; see also $[35,46])$. Future studies might focus on measuring predator control-induced changes in the behaviour of predators (such altered foraging times, prey preferences and space use) and prey (such as selection of non-preferred or safe resources of lesser quality) that may have subtle effects on prey fitness and long-term population viability not detectable in our experiments.

\section{Methods}

Our investigation of the relationships between dingo control and prey (R6 in Figure 1) occurred simultaneously with our investigation of the relationships between dingo control and predators (R1, R2 and R4 in Figure 1), as previously reported in Allen et al. [25]. As such, our description of the methods used in the present study is based heavily on that study. All procedures described were sanctioned by the relevant animal care and welfare authorities for each site (Queensland Department of Natural Resources' Pest Animal Ethics Committee, PAEC 930401 and PAEC 030604; South Australian Department 


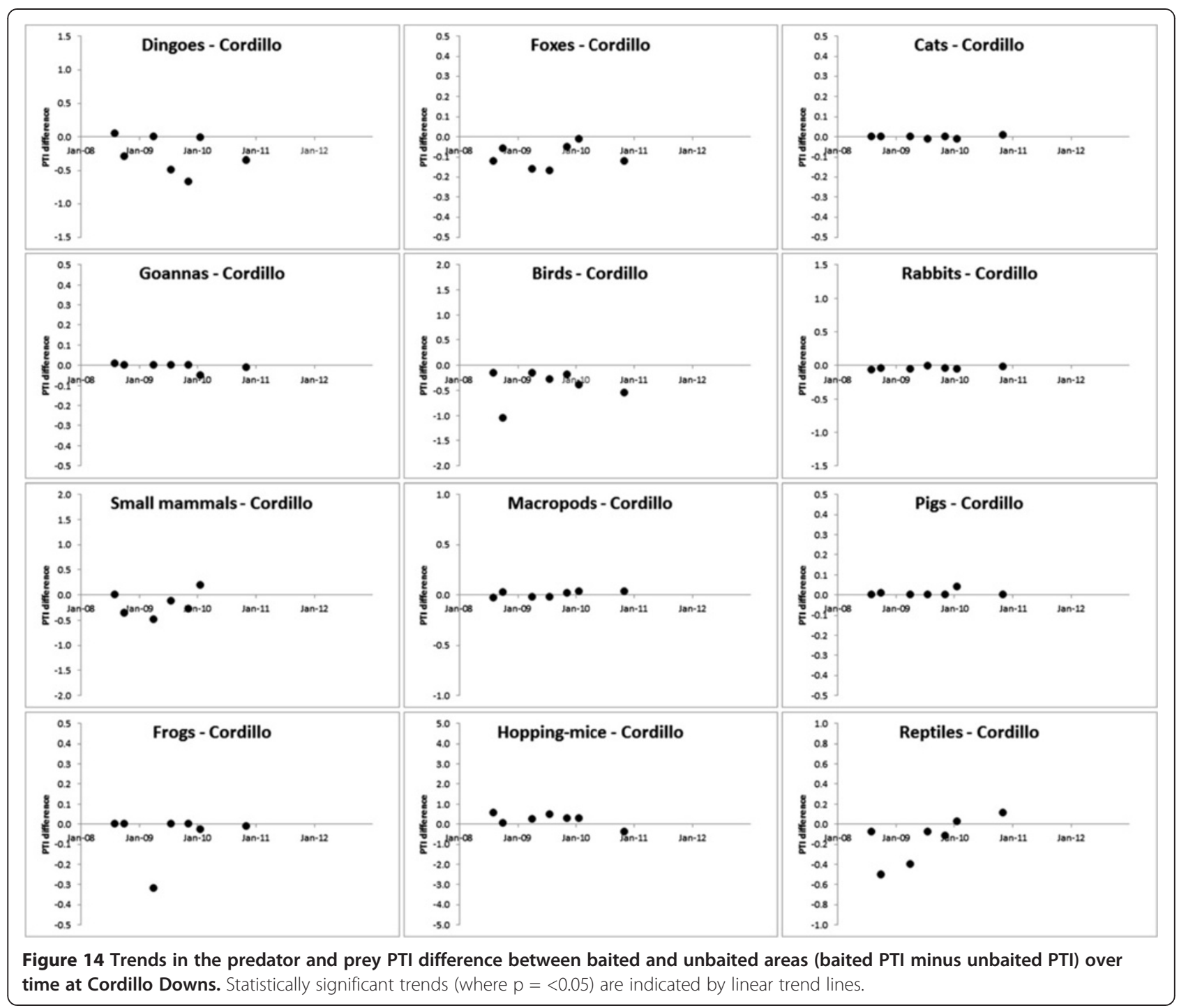

of Environment and Heritage's Wildlife Ethics Committee, WEC 16/2008).

\section{Study sites and design}

We conducted a series of large-scale, multi-year, predatormanipulation experiments on extensive beef-cattle producing properties in five different land systems representing the breadth of the beef-cattle rangelands of Australia, where mean rainfall varied from 160-772 mm annually, or from arid to tropical areas (see Figure Seven and Table Six in [25]). Seasonal conditions fluctuated between periods of above- and below-average rainfall, or between drought and flush periods at each site during our experiments (Figure 21).

Using paired nil-treatment areas without dingo control for comparison (see Figure EightA in [25]), we examined the relative abundances of prey (and predators) in paired areas subjected to periodic broad-scale poisonbaiting for dingoes at six of nine study sites (Strathmore, Mt Owen, Cordillo Downs, Quinyambie, Todmorden and Lambina; see Table Six in [25]), referred to as the six experimental sites. Aerial and/or ground-laid sodium fluoroacetate (or '1080') poison-baits were distributed individually (spaced at least $300 \mathrm{~m}$ apart) along landscape features (e.g. drainage lines, ridges, fragment edges etc.) and/or unformed dirt roads or tracks according to local practices and regulations up to five times each year (typically once in spring and again in autumn at the six experimental sites, and every 2-4 months continuously at the other three sites). Baits were distributed over a 1-2 day period to a midway point in the buffer zone between treatments (described below; see also Figure EightA in [25]). Each bait weighed 100-250 g and contained at least $6 \mathrm{mg}$ of 1080 , 


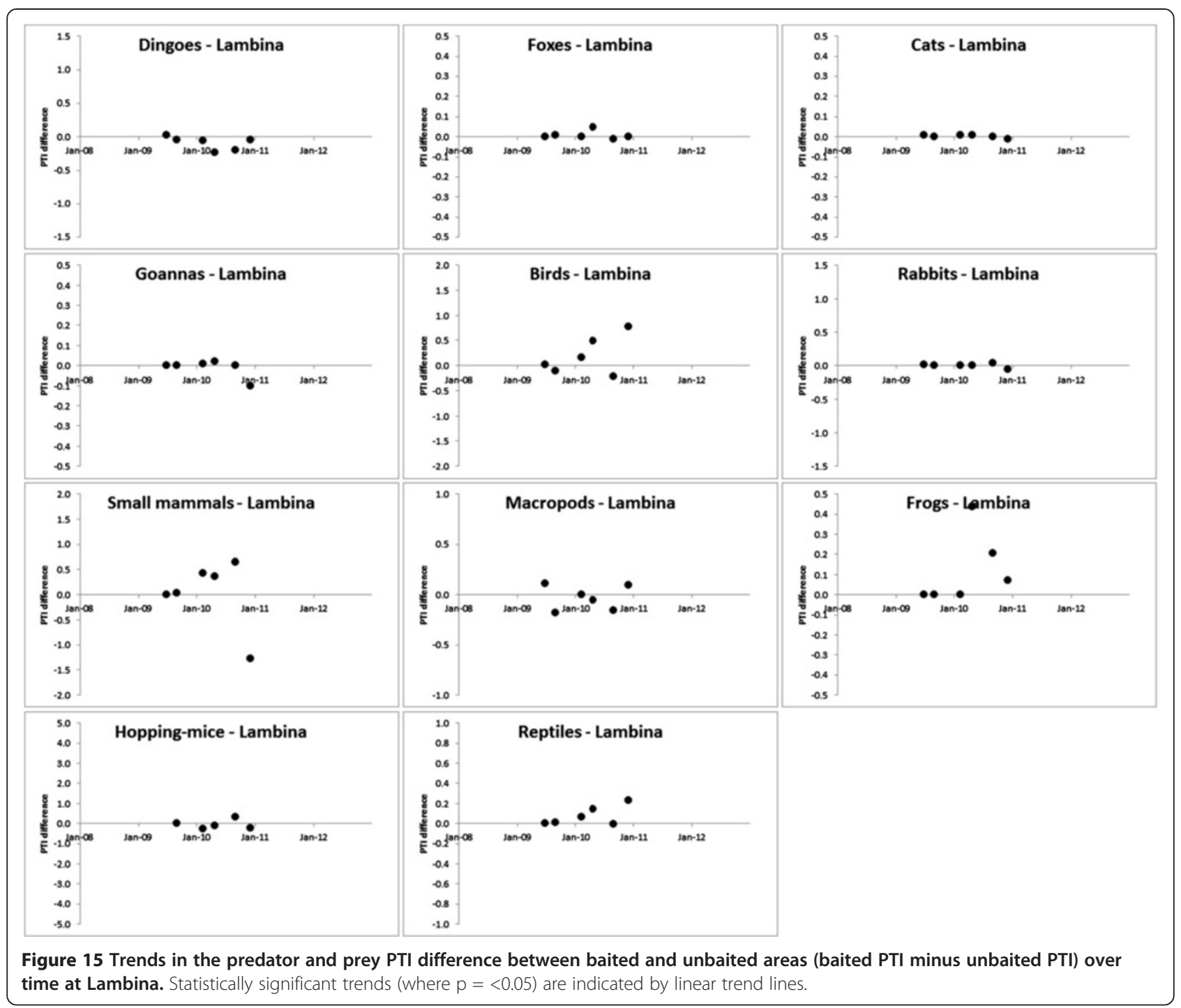

sufficient to kill adult dingoes, foxes or cats if consumed soon after bait distribution [99]. Such spatially and temporally sporadic baiting practices are common, occur widely across Australia, and are considered the only effective dingo and fox control tool used in rangeland areas $[31,100]$. Populations of all other extant fauna at our sites are typically not susceptible to such baiting practices because they are either tolerant of the toxin at the low-level doses used in dingo baits and/or rarely consume carrionlike baits, preferring live prey instead (e.g. [60,61,101]).

Experimental treatment (i.e. baited) and nil-treatment (i.e. unbaited) areas were randomly allocated. Treatment and nil-treatment areas were also replicated in some land systems (see Table Six in [25]). Hone [44] defines this study design as an 'unreplicated experiment' or a 'classical experiment' for our site with replication (i.e.
Todmorden and Lambina might be considered a single site with two treatments and two controls). Both treatment and nil-treatment areas at three of the six experimental sites were historically exposed to baiting up until the commencement of the experiment, whereas, both treatment and nil-treatment areas were not historically exposed to baiting at the other three experimental sites (see Table Six in [25]). Such different baiting histories were necessary to investigate the responses of prey to either the commencement or cessation of baiting, or to the 'removal' or 'addition' of predators (i.e. dingoes and foxes were killed at some sites or allowed to increase at others).

The other three sites (Barcaldine, Blackall and Tambo; referred to as the Blackall sites) were monitored for a similar length of time (see Table Six in [25]), but differed 


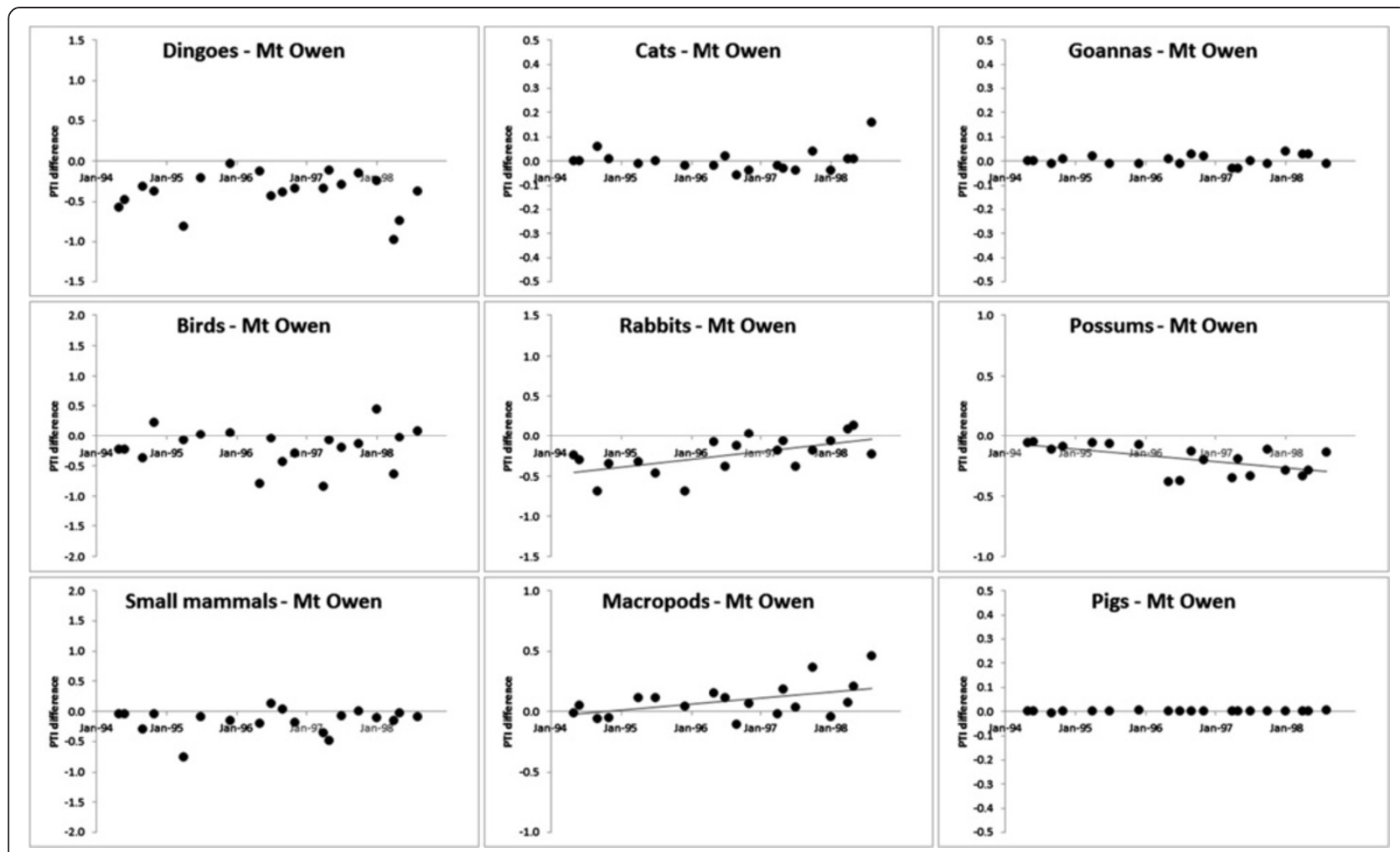

Figure 16 Trends in the predator and prey PTI difference between baited and unbaited areas (baited PTI minus unbaited PTI) over time at Mt Owen. Statistically significant trends (where $p=<0.05$ ) are indicated by linear trend lines.

from the six experimental sites in that the treatments and nil-treatments had already been established for over 10 years and they did not have buffer zones between them (see Figure EightB in [25]). This allowed an assessment of the longer-term outcomes of dingo control. Treatment size, independence and baiting practices therefore varied between the nine sites in order to deliver in situ tests which reflected contemporary dingo control practices within each bioregion. Experiments were conducted at large spatial scales, where the size of the total treatment and nil-treatment area at each of the nine sites ranged between $800 \mathrm{~km}^{2}$ and $9,000 \mathrm{~km}^{2}$, or $45,600 \mathrm{~km}^{2}$ in total (see Table Six in [25]). The mean property size of properties that bait in north Queensland (where several of our study sites were located) is $400 \mathrm{~km}^{2}$, and is substantially less elsewhere in Queensland (Queensland Department of Agriculture, Forestry and Fisheries, unpublished data). The size of the baited treatment areas sampled in our experiments ranged from $400 \mathrm{~km}^{2}$ to $4,000 \mathrm{~km}^{2}$ (Table Six in [25]). Thus, the sizes of our baited treatment areas represent areas of similar size or up to 10 times larger than those commonly subjected to baiting. Each site was separated by $100-1,500 \mathrm{~km}$, except in the case of Todmorden and
Lambina, which were neighbouring properties (see Figure Seven in [25]).

\section{Prey population monitoring}

Prey populations were simultaneously monitored in treatment and nil-treatment areas using passive tracking indices (PTI; [102]), which are commonly used to monitor a variety of ground-dwelling mammals, reptiles and birds both in Australia and elsewhere around the world (e.g. [37,38,88,103-105]. We monitored populations of native and exotic amphibians, reptiles, ground-foraging birds and mammals of various sizes from small rodents $(\sim 15 \mathrm{~g})$ to large herbivores such as kangaroos (Macropus spp.) and feral pigs using this technique. Larger feral herbivores (e.g. camels Camelus dromedarius, donkeys Equus asinus, and horses Equus caballus) were also recorded on sand plots on a few occasions, but were excluded from analyses because PTI values for these species are confounded by the effects of humans (e.g. culling and harvesting actions), and nor are these very large species likely to be affected by dingoes to any great degree, or vice versa [106].

PTI surveys were conducted several times each year at each site and were repeated at similar times each 


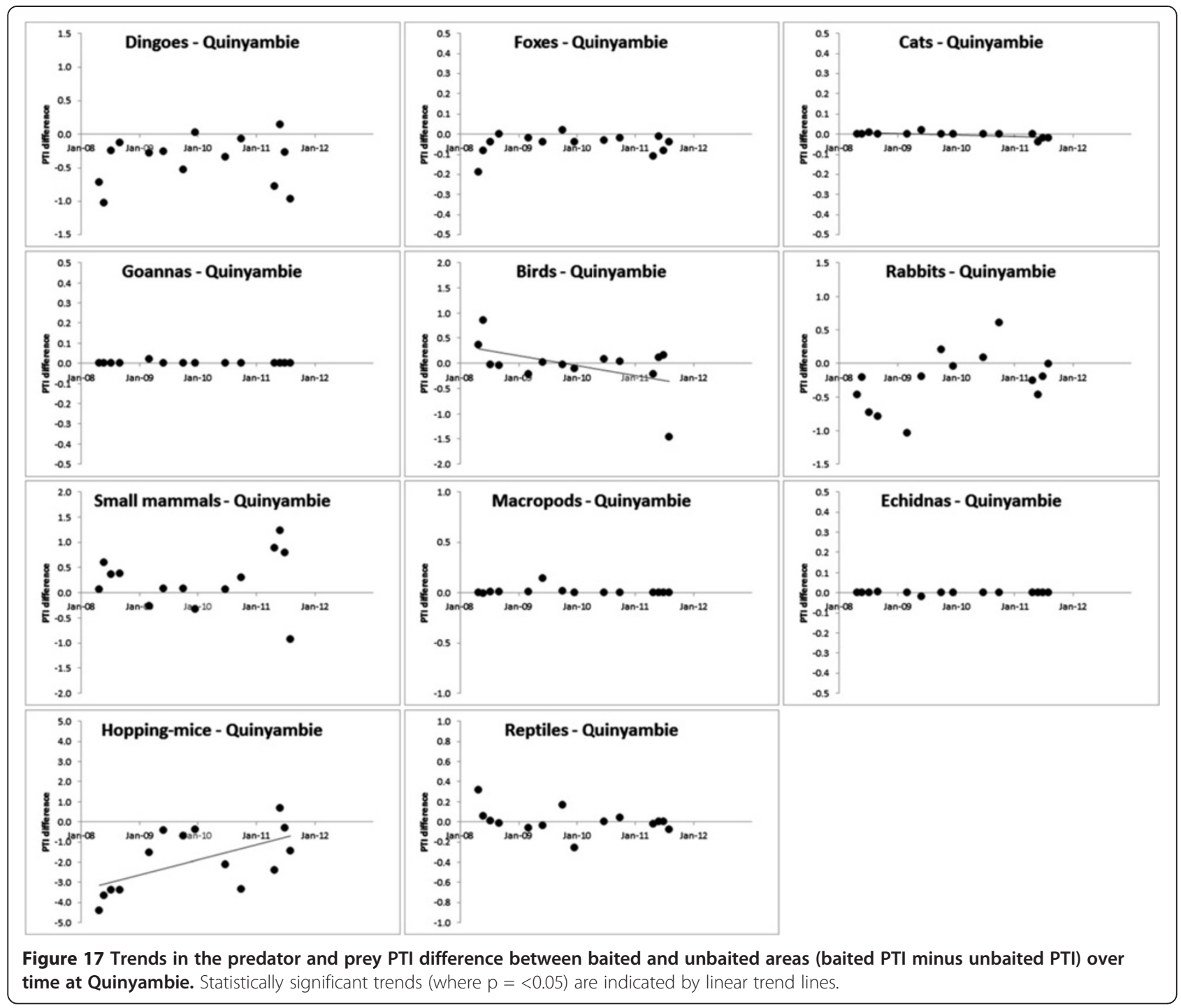

subsequent year over a 2-5 year period (see Table Six in [25]). At the Blackall sites, between 92 and 166 passive tracking plots (or 'sand plots') were spaced at $1 \mathrm{~km}$ intervals along unformed vehicle tracks. At the six experimental sites, 50 plots each were similarly established in both the treatment and nil-treatment areas (i.e. 100 plots per site). For any given survey, plots in both treatments were read and refreshed at the same time daily by the same experienced observer and were monitored for up to 10 successive days (usually $2-5$ ). The location of the first tracking plot in each treatment area was randomly allocated and plots were distributed throughout a similar suite of microhabitat types in both treatment areas. Plots rendered unreadable to one or more species by wind, rain or other factors were excluded from analyses. All predator and prey track intrusions were counted (i.e. a continuous measure). However, the tracks of irruptive small mammals and hopping-mice were limited to a maximum value of 15 tracks per plot per day, which represented saturation of the sand plot with their tracks (i.e. their populations were super-abundant). PTI values for a given survey therefore represented the mean number of prey track intrusions per sand plot tracking station per $24 \mathrm{hr}$ period (i.e. the mean of daily means; [102]). PTIs collected in this way can be reliably interpreted as robust estimates of relative abundance if analysed appropriately (e.g. $[66,77,87]$, but see [107] for an alternative view).

At least one PTI survey was conducted before the imposition of treatments (i.e. before commencement or cessation of baiting in a given treatment) at the six experimental sites to identify any underlying spatial variation in prey population abundances between treatments prior to manipulations. Tracking plot transects at these six sites were separated by a buffer zone $10-50 \mathrm{~km}$ wide 


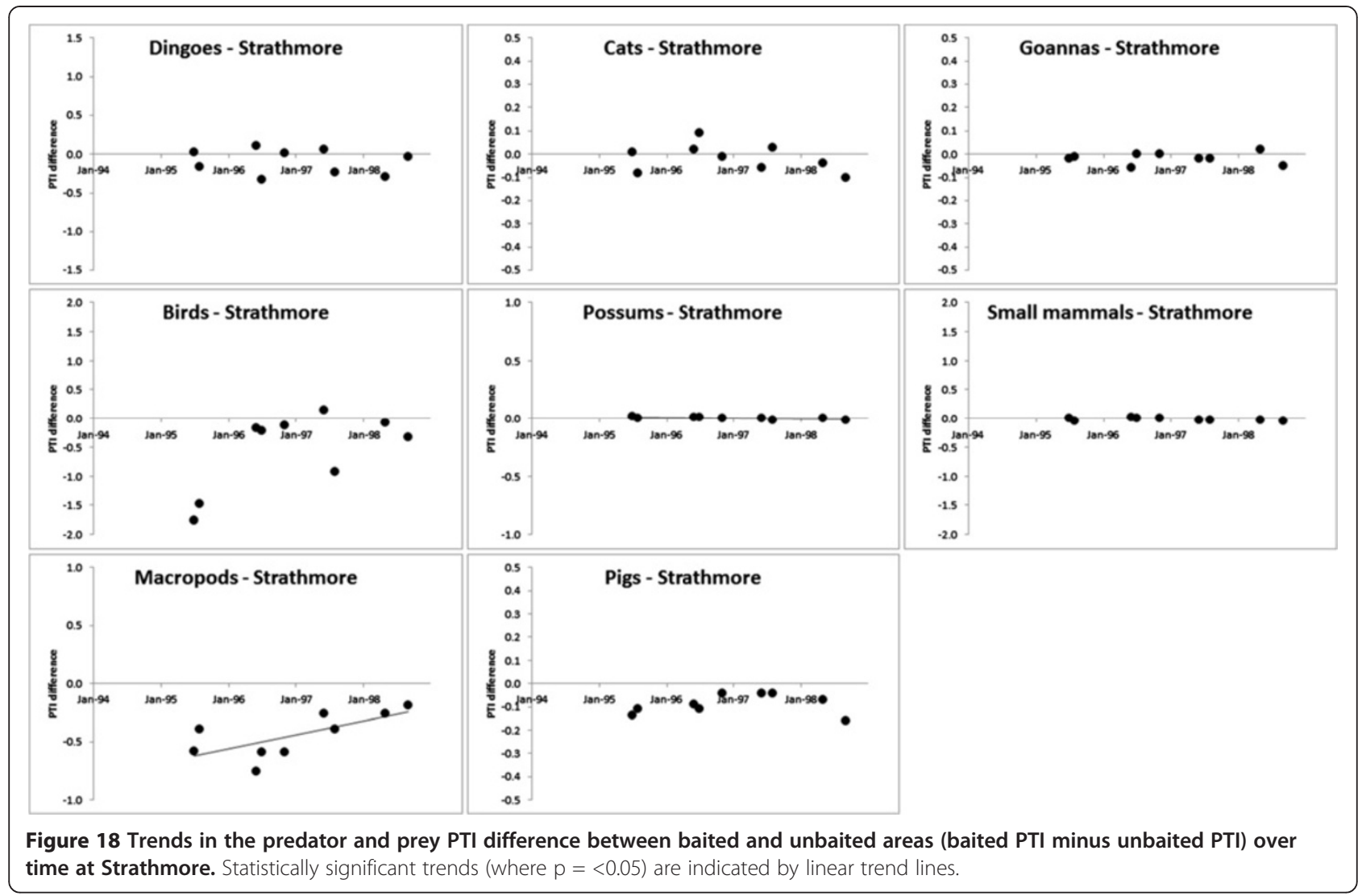

to achieve treatment independence during individual surveys (see Figure Eight in [25]). The appropriate width of the buffer zone at each site was based on the width of 1-2 dingo home ranges in the study areas (e.g. [54,91,108]). Tracking plots were located no closer than $5-25 \mathrm{~km}$ from the edge of the treatment area (i.e. half the width of the buffer zone) to minimise potential edge effects. Overall, we obtained 35,399 plot-nights of tracking data from 128 surveys conducted over 31 site-years (Table 6; see also Table Six in [25]).

\section{Analytical approaches}

Given that each site represented a unique combination of factors including experimental design (experiment or correlation), sampling intensity ( $\mathrm{N}$ surveys ranged from 6-23), mean annual rainfall (160-772 mm), land system (five different types), treatment size or scale (800$9,000 \mathrm{~km}^{2}$ ), baiting context (five different types), baiting frequency (three different types), baiting history (three different types), climate trend during the study period (three different types), and the decade the study was conducted (different sites were sampled up to 30 years apart), reliably assessing their relative effects separately was not possible for most of these factors. Moreover, a given species (e.g. dingoes) or species group (e.g. small mammals or birds) is also not reliably comparable across sites $[87,109]$. In the case of species groups, actual PTI values may represent different species (e.g. rodents or dasyurids), which may have completely different life histories [49] and expected responses to predator control. Food web complexity also alters the expected outcomes of predator population changes $[67,68]$, which is why individual species also exist within a unique fauna assemblage that is not equal or comparable across sites. For example, house mouse (Mus musculus) populations living at a site with only one common predator and one common rodent competitor (e.g. Quinyambie) are unlikely to respond to predator control in the same way as a house mouse population at a site with three common predators and multiple small mammal competitors (e.g. Mt Owen). Furthermore, prey could not be reliably grouped into functional groups such as 'dingo prey', 'fox prey', 'cat prey' or 'not preyed upon by predators' given that each of these predators are generalists and have extensive dietary overlap (i.e. they each eat and threaten the same prey species; [110-113], but see [51]). For these reasons, different species or species groups cannot be 


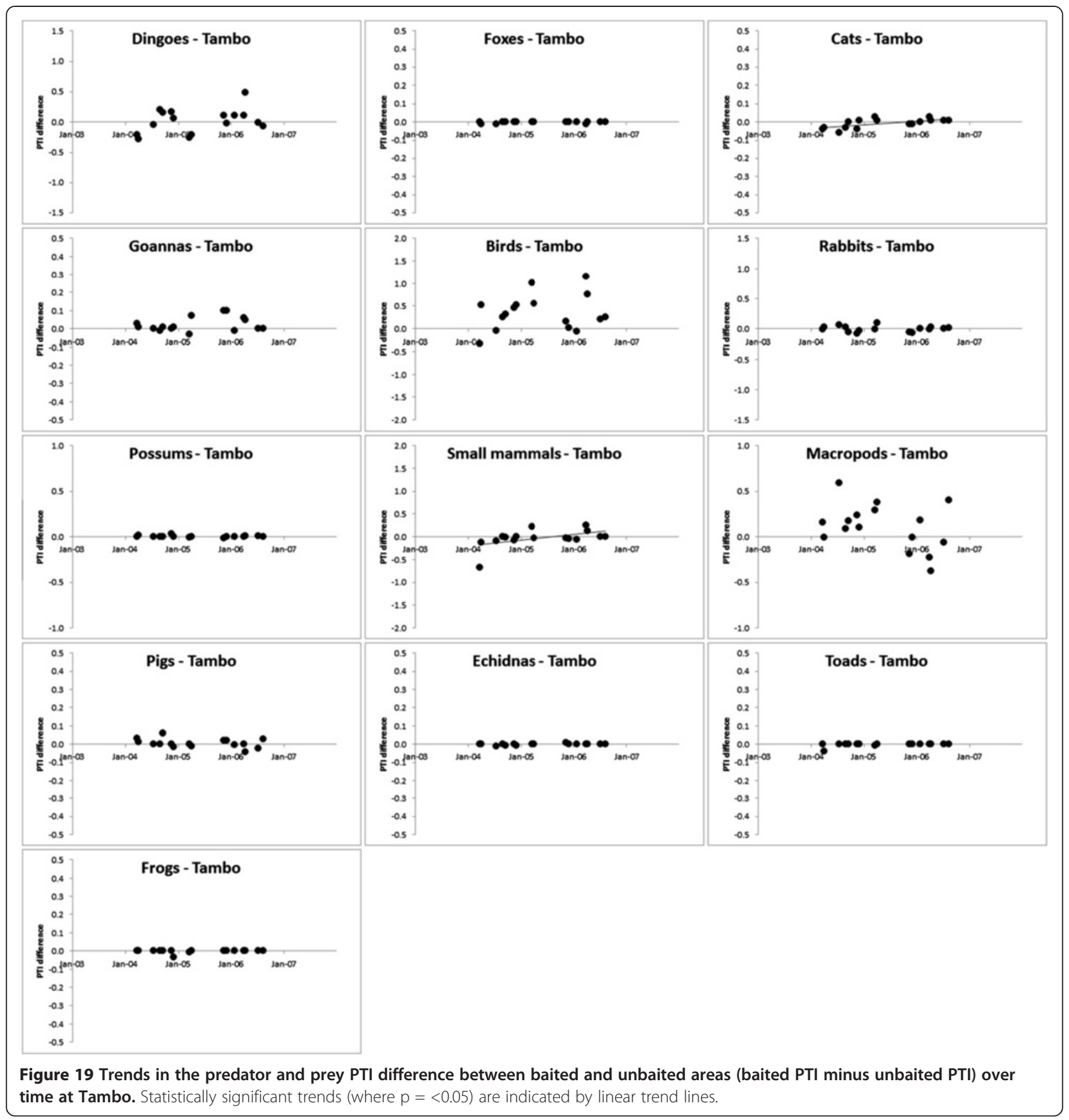

considered equal between sites and should not be pooled across sites as if they were equal.

These limitations meant that only 'baiting history' and 'treatment' offered reliable variables on which to block or pool data across sites, for a given species or species group. Thus, to avoid a complicated variety of site-, context- and species-specific analytical approaches, we consistently applied a conservative three-step logical approach to examine the effects of lethal dingo control on sympatric prey populations at each site.

In Step 1, we first used linear mixed model analyses (using SAS PROC MIXED) to investigate the influence of baiting history (i.e. historically baited in both treatments before cessation of baiting in the unbaited area, historically unbaited in both treatments before baiting commenced in the baited area, or consistent baiting 


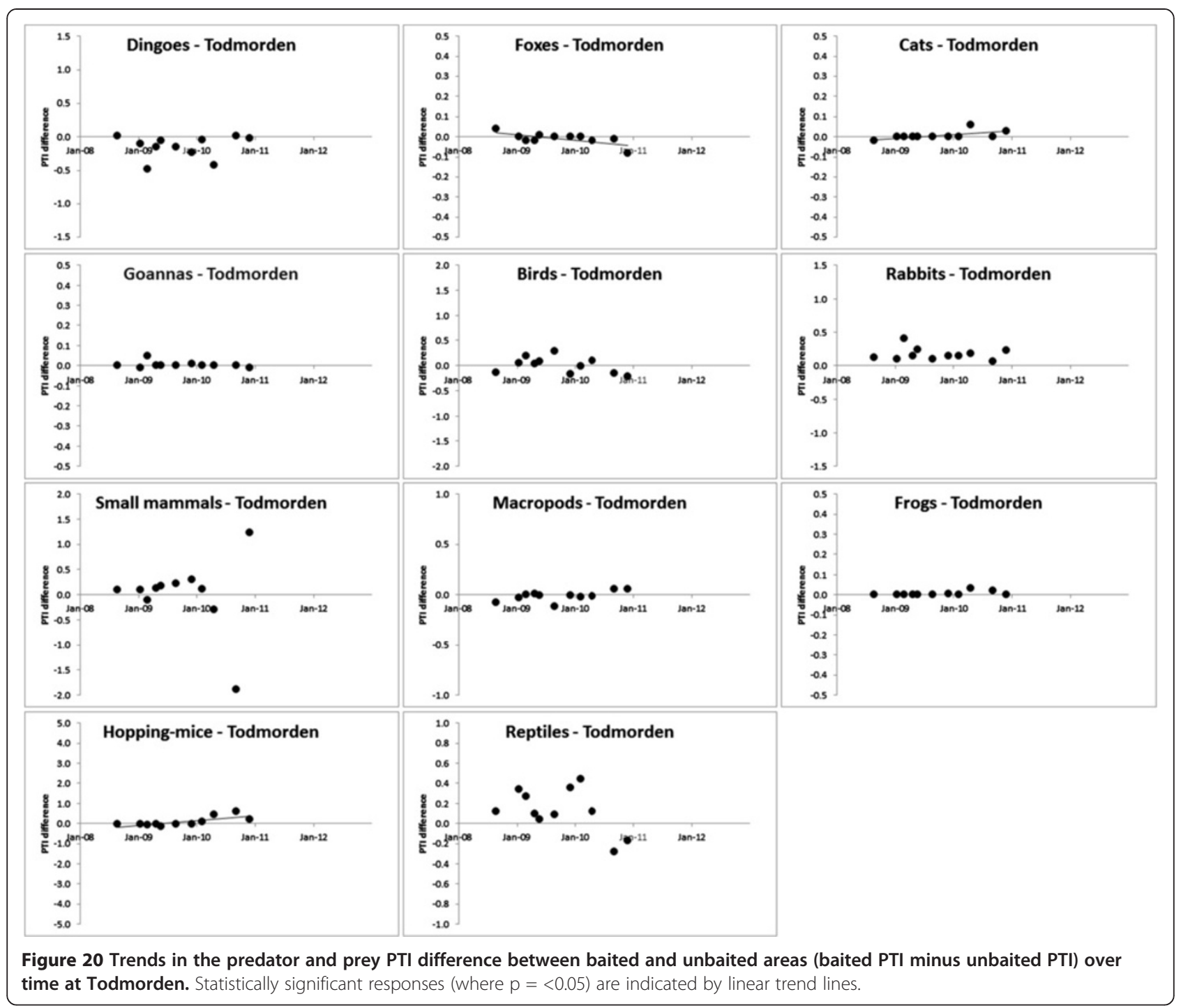

histories for over 10 years; $\mathrm{N}=3$ properties for each), treatment (baited or unbaited) and their interaction on both the overall mean and median PTI for predators and prey. Medians were assessed to address potential issues related to the non-symmetrical distributions of PTI values for some species [89]. Means were assessed for comparative purposes. Results from these analyses yielded little useful information for determining the responses of prey to predator control because the other factors identified above hide or confound any responses that might actually be present. Thus, subsequent analyses focused in detail on individual 'site $\mathrm{x}$ species' combinations in order to explicitly identify which (if any) species responded to dingo control at a given site.

We then compared the mean PTI of prey (both overall and also stratified by season) between baited and unbaited areas at each site using repeated measures ANOVA. That the data are 'approximately normally distributed' is one of the assumptions underlying this approach [114], and given low-detection of some species at times (Table 6, Figures 3, $4,5,6,7,8,9,10,11)$, we violated this assumption in some cases [89]. However, repeated measures ANOVA is very robust to deviations from normality, with non-normal distributions seldom affecting the overall outcomes or interpretations [114-116]. Severe deviation from normality can lead to lower $\mathrm{p}$ values, or an increased probability of type I errors or false positives. For our study, this simply means that some of the few reported differences in overall mean prey PTI between baited and unbaited areas (Tables 2 and 3) may not be real [89]. This first step determines crude differences in prey PTI between treatments but cannot identify causal factors for any observed differences. 
Table 5 Correlations ( $r$, with $p$ values in parentheses) for relationships in longer-term predator PTI trends between baited and unbaited areas at nine sites across Australia (see also Figure Two in [25])

\begin{tabular}{lllll}
\hline Site & Dingoes & Foxes & Cats & Goannas \\
\hline Barcaldine & $0.6174(0.0017)$ & $0.1930(0.3777)$ & $0.2962(0.1700)$ & $0.3682(0.0838)$ \\
Blackall & $0.6409(0.0017)$ & $0.5137(0.0172)$ & $0.2660(0.2437)$ & $-0.3321(0.1413)$ \\
Cordillo & $-0.0919(0.8446)$ & $0.2185(0.6379)$ & $-0.2582(0.5761)$ & $0.6285(0.1306)$ \\
Lambina & $0.5761(0.3094)$ & $-0.0199(0.9746)$ & $0.7845(0.1162)$ & $-0.3542(0.5587)$ \\
Mt Owen & $0.6152(0.0051)$ & $0.2679(0.2674)$ & $0.6828(0.0013)$ & $0.9518(0.0000)$ \\
Quinyambie & $0.4028(0.1533)$ & $0.4199(0.1350)$ & $-0.1627(0.5785)$ & $X$ \\
Strathmore & $0.4313(0.2464)$ & $\mathrm{NP}$ & $0.4393(0.2368)$ & $0.7577(0.0180)$ \\
Tambo & $0.2969(0.2642)$ & $X$ & $0.9564(0.0000)$ & $0.2254(0.4013)$ \\
Todmorden & $0.1463(0.6678)$ & $0.0145(0.9663)$ & $0.3002(0.3698)$ & $0.6259(0.0394)$ \\
\hline
\end{tabular}

$\mathrm{NP}=$ not present; ND = known to be present but not detected on tracking plots; $\mathrm{BP}=$ believed present but not detected on tracking plots; NR $=$ present and detected on tracking plots but not recorded; RE = Mostly Varanus spp. and reported in [25]; *All reptiles except for Varanus spp. (i.e. predominately agamidae and skincidae); ^All dasyurids and rodents except for hopping-mice; N surveys per site are given in Table 2.

In Step 2, we determined short-term changes in prey PTI values between pre- and post-baiting surveys by assessing mean net changes in PTI (i.e. changes in the baited area after accounting for changes in the unbaited area) with one-factor repeated measures analyses, or t-tests. To ensure maximum analytical power, this was done for each site where at least four pre- and post-baiting surveys were conducted. This step identifies any short-term responses to baiting and their cause (i.e. baiting) but cannot determine whether or not these observed responses are sustained over longer timeframes. Greater detail on the resilience of dingoes to lethal control and the factors affecting the efficacy of individual baiting programs can be found elsewhere in $[19,47,85]$.

In Step 3, we assessed (1) temporal correlations between predator and prey abundance trends in baited and unbaited areas and (2) whether or not the difference in species' PTI values between baited and unbaited areas increased, decreased or did not change over time. This third and final step assesses whether or not population trends in baited and unbaited areas fluctuate synchronously, identifies causal factors (i.e. baiting), and determines whether or not predator or prey population trends in baited and unbaited areas are diverging or converging over longer timeframes. Step 3 is the most conclusive of our analyses for determining the responses of predators and prey to baiting.

This three-step analytical approach was designed to assess the outcomes of baiting at each site for each species, and was not designed to assess the relative influence of the many other factors that might also influence predator and prey population dynamics, such as rainfall and those others mentioned above (e.g. $[117,118])$. Analyses were performed using all available data. However, data were not available for all prey species at all sites because the distribution of various species does not extend to all sites [49] or because extant species were not detected on tracking plots or recorded (Table 6). For example, though they were present at some sites, no analyses could be performed on koalas (Phascolarctos cinereus) due to insufficient data (Table 6). Additional details on the sensitivity and reliability of our methods can be found in Allen et al. [25,89] or Allen [85,119] and Allen [19].

\section{Predicted outcomes (which seldom, if ever, occurred; see Results)}

Whether through numerical and/or functional changes to predator and/or prey populations, overall negative effects of lethal top-predator control on prey populations are expected to be manifest as a numerical decline in prey population abundance indices in baited areas (e.g. $[13,32,33])$. Thus, our three-step analytical approach would detect dingo control-induced prey declines where dingo PTI trends diverge or converge and:

1. Mean overall prey PTI is lower in baited areas (potentially indicative of greater mesopredator abundances and predation pressure on prey in baited areas)

2. Mean net prey PTI significantly decreases shortly after dingo control (potentially indicative of an immediate increase in mesopredator activity, predation pressure on prey or fear-induced behavioural avoidance of predators by prey)

3. (A) Prey PTI trends are negatively correlated over time between treatments and/or (B) divergence or convergence of PTI trends is apparent (potentially indicative of longer-term dingo control-induced prey declines). 
Table 6 The total number of prey tracks observed in paired baited and unbaited areas at nine sites in Australia

\begin{tabular}{|c|c|c|c|c|c|c|c|c|c|c|c|c|c|c|}
\hline Site & Treatment & Plotnights & Birds & Rabbits & Possums & Small mammals $\wedge$ & Macropods & Pigs & Echidnas & Koalas & Toads & Frogs & Hopping mice & Reptiles* \\
\hline \multirow{2}{*}{ Barcaldine } & B & 3015 & 998 & 1005 & 17 & 901 & 1901 & 29 & 24 & \multirow{2}{*}{ BP } & 10 & 24 & \multirow{2}{*}{ NP } & \multirow{2}{*}{ RE } \\
\hline & UB & 3131 & 921 & 608 & 2 & 703 & 1969 & 3 & 9 & & 2 & 10 & & \\
\hline \multirow{2}{*}{ Blackall } & B & 809 & 187 & 120 & 1 & 185 & 348 & 1 & 5 & \multirow{2}{*}{$\mathrm{BP}$} & \multirow{2}{*}{ ND } & 2 & \multirow{2}{*}{ NP } & \multirow{2}{*}{ RE } \\
\hline & UB & 3271 & 808 & 473 & 2 & 749 & 762 & 8 & 19 & & & 19 & & \\
\hline \multirow{2}{*}{ Tambo } & B & 1352 & 1001 & 93 & 5 & 222 & 782 & 17 & 1 & \multirow{2}{*}{$\mathrm{BP}$} & 0 & 2 & \multirow{2}{*}{$N P$} & \multirow{2}{*}{ RE } \\
\hline & UB & 2130 & 901 & 148 & 4 & 448 & 960 & 13 & 3 & & 6 & 11 & & \\
\hline \multirow{2}{*}{ Mt Owen } & B & 4389 & 4554 & 1292 & 175 & 1442 & 1512 & 2 & 1 & 2 & \multirow{2}{*}{ NR } & \multirow{2}{*}{ NR } & \multirow{2}{*}{ NP } & \multirow{2}{*}{ RE } \\
\hline & UB & 4350 & 5549 & 2229 & 1048 & 2186 & 1157 & 1 & 1 & 1 & & & & \\
\hline \multirow{2}{*}{ Strathmore } & B & 2066 & 4254 & ND & 32 & 21 & 200 & 89 & 3 & \multirow{2}{*}{$\mathrm{BP}$} & \multirow{2}{*}{ NR } & \multirow{2}{*}{ NR } & \multirow{2}{*}{ NP } & \multirow{2}{*}{ RE } \\
\hline & UB & 2186 & 5633 & & 26 & 53 & 1183 & 295 & 0 & & & & & \\
\hline \multirow{2}{*}{ Lambina } & B & 750 & 380 & 11 & \multirow{2}{*}{ NP } & 1128 & 127 & \multirow{2}{*}{ NP } & \multirow{2}{*}{ ND } & \multirow{2}{*}{ NP } & \multirow{2}{*}{ NP } & 106 & 276 & 132 \\
\hline & UB & 750 & 275 & 10 & & 1051 & 152 & & & & & 24 & 303 & 84 \\
\hline \multirow{2}{*}{ Quinyambie } & B & 1400 & 1026 & 922 & \multirow{2}{*}{ NP } & 1942 & 12 & $N R$ & 1 & $A P$ & $N P$ & 0 & 6105 & 213 \\
\hline & UB & 1400 & 948 & 1234 & & 1554 & 1 & NOU & 1 & $T N \Gamma$ & $\mathrm{TNI}$ & 3 & 8883 & 190 \\
\hline Cordillo Downs & B & 900 & 134 & 16 & $N P$ & 593 & 25 & 7 & N & $A P$ & NP & 0 & 356 & 136 \\
\hline Coramio Downs & UB & 900 & 459 & 53 & $\mathrm{NPP}$ & 980 & 20 & 0 & NO & $\mathrm{NPP}$ & $\mathrm{NPP}$ & 37 & 130 & 252 \\
\hline Todmorden & B & 1300 & 496 & 221 & $N P$ & 1366 & 89 & $N P$ & $\mathrm{~N}$ & $N P$ & $N P$ & 8 & 393 & 377 \\
\hline Toamoraen & UB & 1300 & 470 & 9 & $\mathrm{NPP}$ & 1333 & 108 & TNP & NND & $\mathrm{NPP}$ & $\mathrm{NPP}$ & 0 & 272 & 173 \\
\hline Grand Total & & 35399 & 28995 & 8444 & 1312 & 16857 & 11308 & 465 & 68 & 3 & 18 & 246 & 16718 & 1557 \\
\hline
\end{tabular}

${ }^{*}=$ Greater in baited areas; $\wedge$ = greater PTI in unbaited areas; NP = not present; ND = known to be present but not detected on tracking plots; $\mathrm{NR}=$ present and detected but not recorded; RE = mostly Varanus spp. and reported in [25]; $X=$ insufficient data to calculate $\mathrm{p}$; $\mathrm{N}$ surveys for hopping-mice at Lambina $=2$, error $\mathrm{df}=1$ for hopping-mice. 


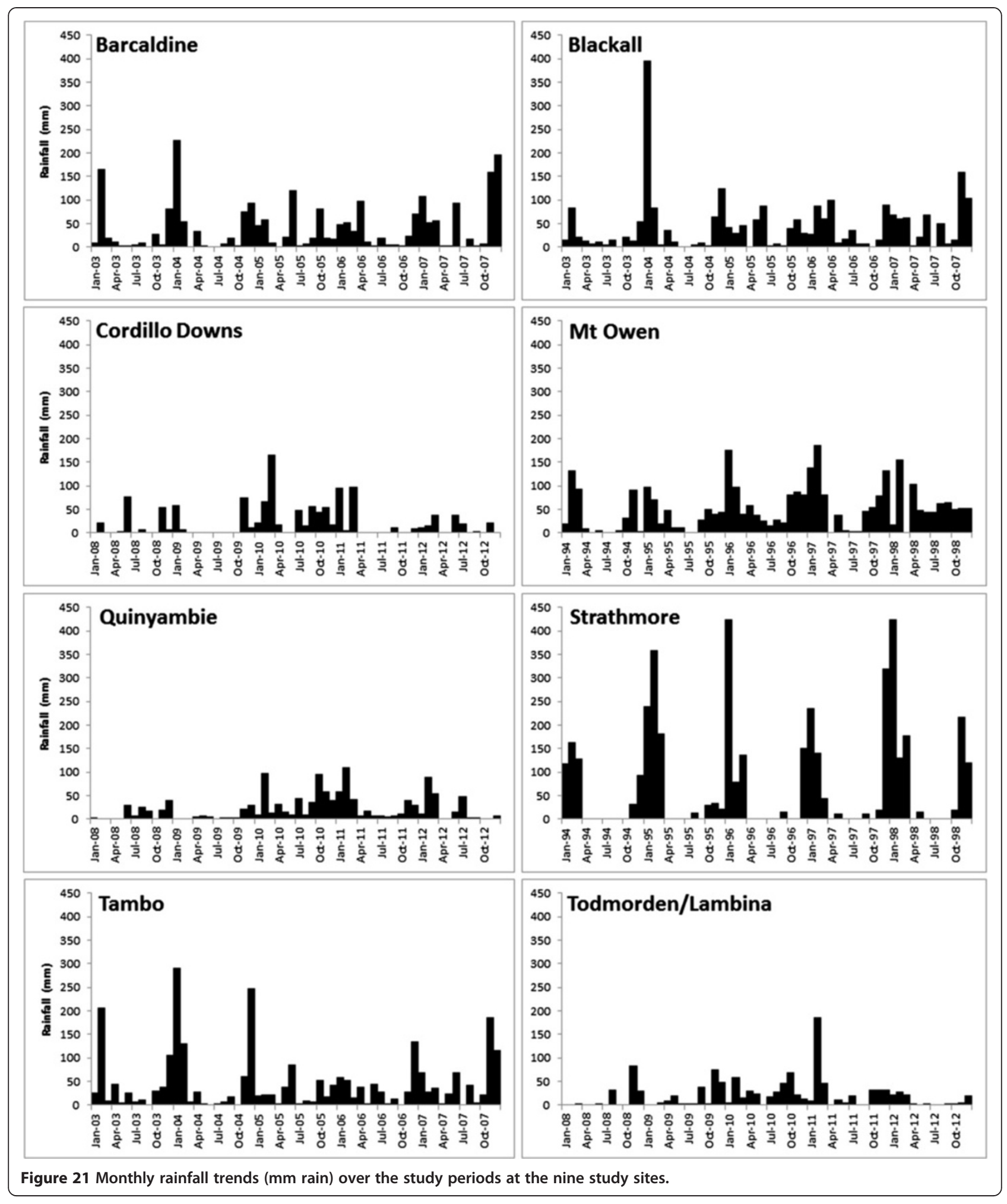




\section{Availability of supporting data}

All PTI values obtained during our study are presented in the tables and figures.

\author{
Abbreviations \\ PTI: Passive tracking index; ANOVA: Analysis of variance.
}

\section{Competing interests}

The authors declare that they have no competing interests.

\section{Authors' contributions}

LA designed and supervised the study. BA and LA collected field data and performed preliminary analyses. BA performed the remaining analyses, constructed the tables and figures and wrote the majority of the manuscript. RE performed statistical analyses. $L A, R E$ and $L L$ contributed further to the writing of the manuscript. All authors read and approved the final manuscript.

\section{Acknowledgements}

Generous in-kind support and hospitality was freely provided by the owners and managers of the beef-cattle properties on which we worked - this research would not have been possible without them. Damien Byrne, Heather Miller, James Speed, Steve Eldridge and Tony Gonzales assisted in the collection of field data. Analytical and editorial advice on earlier drafts of the paper was provided by Joe Scanlan, Matt Gentle and Matt Hayward. Allan Lisle provided additional statistical advice. Al Glen, Camilla Myers, Dane Panetta, Glen Saunders, Greg Campbell, Jim Hone, John Read, Peter Bird, Peter Fleming, Simon Humphrys and Tony Pople provided advice on the associated study of Allen et al. [25], which advice was further used to shape aspects of this related paper as well. Generous funding for components of this study was provided by the following Australian Government funding sources: Bureau of Resource Sciences, Caring for Our Country, and Natural Heritage Trust. These funding bodies had no role in the design, implementation, analysis or publication of this study. Some of this funding was administered by the South Australian Arid Lands Natural Resources Management Board. The production of this report was undertaken as part of work supported by the Invasive Animals Cooperative Research Centre.

\section{Author details}

${ }^{1}$ School of Agriculture and Food Sciences, The University of Queensland, Warrego Highway, Gatton, QLD 4343, Australia. ${ }^{2}$ Robert Wicks Pest Animal Research Centre, Biosecurity Queensland, Tor Street, Toowoomba, QLD 4350, Australia. ${ }^{3}$ National Wildlife Research Centre, US Department of Agriculture, LaPorte Avenue, Fort Collins, CO 80521-2154, USA.

Received: 11 March 2014 Accepted: 25 July 2014

Published: 16 September 2014

\section{References}

1. Tscharntke T, Clough Y, Wanger TC, Jackson L, Motzke I, Perfecto I, Vandermeer J, Whitbread A: Global food security, biodiversity conservation and the future of agricultural intensification. Biol Conserv 2012, 151:53-59.

2. Tylianakis JM, Didham RK, Bascompte J, Wardle DA: Global change and species interactions in terrestrial ecosystems. Ecol Lett 2008, 11:1351-1363.

3. McKenzie NL, Burbidge AA, Baynes A, Brereton RN, Dickman CR, Gordon G, Gibson LA, Menkhorst PW, Robinson AC, Williams MR, Woinarski JCZ: Analysis of factors implicated in the recent decline of Australia's mammal fauna. J Biogeogr 2007, 34:597-611.

4. Ritchie EG, Johnson CN: Predator interactions, mesopredator release and biodiversity conservation. Ecol Lett 2009, 12:982-998.

5. Crooks KR, Soulé ME: Mesopredator release and avifaunal extinctions in a fragmented system. Nature 1999, 400:563-566.

6. Estes J, Crooks K, Holt RD: Ecological Role of Predators. In Encyclopedia of Biodiversity, Volume 6. 2nd edition. Edited by Levin SA. Waltham: Academic; 2013

7. Terborgh J, Estes JA: Trophic Cascades: Predator, Prey, and the Changing Dynamics of Nature. Washington D.C: Island Press; 2010.

8. Ripple WJ, Estes JA, Beschta RL, Wilmers CC, Ritchie EG, Hebblewhite M, Berger J, Elmhagen B, Letnic M, Nelson MP, Schmitz OJ, Smith DW, Wallach $A D$, Wirsing AJ: Status and ecological effects of the world's largest carnivores. Science 2014, 343:151-163.
9. Hayward MW, Somers MJ: Reintroduction of Top-order Predators. Oxford: Wiley-Blackwell; 2009.

10. Ritchie EG, Elmhagen B, Glen AS, Letnic M, Ludwig G, McDonald RA: Ecosystem restoration with teeth: what role for predators? Trends Ecol Evol 2012, 27:265-271

11. Sergio F, Caro T, Brown D, Clucas B, Hunter J, Ketchum J, McHugh K, Hiraldo F: Top predators as conservation tools: ecological rationale, assumptions, and efficacy. Annu Rev Ecol Evol Syst 2008, 39:1-19.

12. Ordiz A, Bischof R, Swenson JE: Saving large carnivores, but losing the apex predator? Biol Conserv 2013, 168:128-133.

13. Wallach $A D$, Johnson $C N$, Ritchie EG, O'Neill AJ: Predator control promotes invasive dominated ecological states. Ecol Lett 2010, 13:1008-1018.

14. Fleming PJS, Allen BL, Ballard G: Seven considerations about dingoes as biodiversity engineers: the socioecological niches of dogs in Australia. Australian Mammalogy 2012, 34:119-131.

15. Muhly TB, Hebblewhite M, Paton D, Pitt JA, Boyce MS, Musiani M: Humans strengthen bottom-up effects and weaken trophic cascades in a terrestrial food web. PLOS ONE 2013, 8:e64311.

16. Wright HL, Lake IR, Dolman PM: Agriculture-a key element for conservation in the developing world. Conserv Lett 2012, 5:11-19.

17. Phalan B, Balmford A, Green RE, Scharlemann JPW: Minimising the harm to biodiversity of producing more food globally. Food Policy 2011, 36(Supplement 1):S62-S71.

18. Linnell JDC: The relative importance of predators and people in structuring and conserving ecosystems. Conserv Biol 2011, 25:646-647.

19. Allen BL: The effect of lethal control on the conservation values of Canis lupus dingo. In Wolves: Biology, Conservation, and Management. Edited by Maia AP, Crussi HF. New York: Nova Publishers; 2012:79-108.

20. Valeix M, Hemson G, Loverage AJ, Mills G, Macdonald DW: Behavioural adjustments of a large carnivore to access secondary prey in a human-dominated landscape. J Appl Ecol 2012, 49:73-81.

21. Sidorovich VE, Tikhomirova LL, Jedrzejewska B: Wolf Canis lupus numbers, diet and damage to livestock in relation to hunting and ungulate abundance in northeastern Belarus during 1990-2000. Wildl Biol 2003, 9:103-111.

22. Treves A: Hunting for large carnivore conservation. J Appl Ecol 2009, 46:1350-1356.

23. Chapron G, Miquelle DG, Lambert A, Goodrich JM, Legendre S, Clobert J: The impact on tigers of poaching versus prey depletion. J Appl Ecol 2008, 45:1667-1674.

24. Ritchie EG: The world's top predators are in decline, and it's hurting us too. The Conversation 2014. 10th January 2014, accessed 11th January 2014: available at http://theconversation.com/the-worlds-top-predators-are-indecline-and-its-hurting-us-too-21830.

25. Allen $B L$, Allen $L R$, Engeman RM, Leung LK-P: Intraguild relationships between sympatric predators exposed to lethal control: predator manipulation experiments. Frontiers in Zoology 2013, 10:39.

26. Corbett LK: The Dingo in Australia and Asia. 2nd edition. Marleston: J.B. Books, South Australia; 2001.

27. Allen $B L$, West $P$ : The influence of dingoes on sheep distribution in Australia. Aust Vet J 2013, 91:261-267.

28. Stephens D: The molecular ecology of Australian wild dogs: hybridisation, gene flow and genetic structure at multiple geographic scales, PhD. Australia, Perth: The University of Western Australia; 2011.

29. Corbett LK: Canis lupus ssp. dingo. IUCN 2010. IUCN Red List of Threatened Species. Version 2010.4. www.iucnredlist.org. 2008. Downloaded on 20 April 2011.

30. Allen BL, Higginbottom K, Bracks JH, Davies N, Baxter GS: Balancing dingo conservation with human safety on Fraser Island: the numerical and demographic effects of humane destruction of dingoes. Australas $J$ Environ Manag. In press.

31. Fleming PJS, Allen BL, Allen LR, Ballard G, Bengsen AJ, Gentle MN, McLeod L, Meek PD, Saunders GR: Management of wild canids in Australia: free-ranging dogs and red foxes. In Carnivores of Australia: Past, Present and Future. Edited by Glen AS, Dickman CR. Collingwood: CSIRO Publishing; 2014.

32. Johnson C: Australia's Mammal Extinctions: A 50000 Year History. Melbourne: Cambridge University Press; 2006

33. Wallach AD, Ritchie EG, Read J, O'Neill AJ: More than mere numbers: the impact of lethal control on the stability of a top-order predator. PLOS ONE 2009, 4:e6861.

34. Letnic M, Greenville A, Denny E, Dickman CR, Tischler M, Gordon C, Koch F: Does a top predator suppress the abundance of an invasive mesopredator at a continental scale? Glob Ecol Biogeogr 2011, 20:343-353. 
35. Glen AS, Dickman CR, Soulé ME, Mackey BG: Evaluating the role of the dingo as a trophic regulator in Australian ecosystems. Austral Ecology 2007, 32:492-501.

36. Letnic M, Ritchie EG, Dickman CR: Top predators as biodiversity regulators: the dingo Canis lupus dingo as a case study. Biol Rev 2012, 87:390-413.

37. Arthur AD, Catling PC, Reid A: Relative influence of habitat structure, species interactions and rainfall on the post-fire population dynamics of ground-dwelling vertebrates. Austral Ecology 2013, 37:958-970.

38. Claridge AW, Cunningham RB, Catling PC, Reid AM: Trends in the activity levels of forest-dwelling vertebrate fauna against a background of intensive baiting for foxes. For Ecol Manag 2010, 260:822-832.

39. Eldridge SR, Shakeshaft BJ, Nano TJ: The Impact of Wild Dog Control on Cattle, Native and Introduced Herbivores and Introduced Predators in Central Australia, Final Report to the Bureau of Rural Sciences. Alice Springs: Parks and Wildlife Commission of the Northern Territory; 2002.

40. Allen BL, Lundie-Jenkins G, Burrows ND, Engeman RM, Fleming PJS, Leung LK-P: Does lethal control of top-predators release mesopredators? A re-evaluation of three Australian case studies. Ecol Manag Restor 2014 $15: 1-5$.

41. Barbosa P, Castellanos I: Ecology of Predator-prey Interactions. New York: Oxford University Press; 2005.

42. Allen BL, Fleming PJS, Hayward M, Allen LR, Engeman RM, Ballard G, Leung LK-P: Top-predators as biodiversity regulators: contemporary issues affecting knowledge and management of dingoes in Australia. In Biodiversity Enrichment in a Diverse World, Volume 4. Edited by Lameed GA. Rijeka, Croatia: InTech Publishing; 2012:85-132.

43. Salo P, Banks PB, Dickman CR, Korpimaki E: Predator manipulation experiments: impacts on populations of terrestrial vertebrate prey. Ecol Monogr 2010, 80:531-546.

44. Hone J: Wildlife Damage Control. Collingwood, Victoria: CSIRO Publishing; 2007.

45. Krebs CJ: Ecology: The Experimental Analysis of Distribution and Abundance. 6th edition. San Francisco: Benjamin-Cummings Publishing; 2008.

46. Allen BL, Fleming PJS, Allen LR, Engeman RM, Ballard G, Leung LK-P: As clear as mud: a critical review of evidence for the ecological roles of Australian dingoes. Biol Conserv 2013, 159:158-174.

47. Allen LR: The Impact of Wild Dog Predation and Wild Dog Control on Beef Cattle: Large-scale Manipulative Experiments Examining the Impact of and Response to Lethal Control. Saarbrucken, Germany: LAP Lambert Academic Publishing; 2013

48. Allen LR, Goullet M, Palmer R: The diet of the dingo (Canis lupus dingo and hybrids) in north-eastern Australia: a supplement to Brook and Kutt. The Rangeland Journal 2012, 34:211-217.

49. Van Dyck S, Strahan R: The Mammals of Australia. 3rd edition. Sydney: Reed New Holland; 2008.

50. Allen LR: Wild dog control impacts on calf wastage in extensive beef cattle enterprises. Anim Prod Sci 2014, 54:214-220.

51. Allen BL, Fleming PJS: Reintroducing the dingo: the risk of dingo predation to threatened vertebrates of western New South Wales. Wild Res 2012, 39:35-50.

52. Foulkes JN: The ecology and management of the common brushtail possum Trichosaurus vulpecula in central Australia, PhD. Canberra: The University of Canberra, Applied ecology research group; 2001.

53. Kerle JA, Foulkes JN, Kimber RG, Papenfus D: The decline of the brushtail possum, Trichosurus vulpecula (Kerr 1798), in arid Australia. The Rangeland Journal 1992, 14:107-127.

54. Allen BL, Engeman RM, Leung LK-P: The short-term effects of a routine poisoning campaign on the movement behaviour and detectability of a social top-predator. Environ Sci Pollut Res 2014, 21:2178-2190.

55. Allen $B L$, Leung LK-P: Assessing predation risk to threatened fauna from their prevalence in predator scats: dingoes and rodents in arid Australia. PLOS ONE 2012, 7:e36426.

56. Allen BL: Scat happens: spatiotemporal fluctuation in dingo scat collection rates. Aust J Zool 2012, 60:137-140.

57. Haber GC: Biological, conservation, and ethical implications of exploiting and controlling wolves. Conserv Biol 1996, 10:1068-1081.

58. Webb NF, Allen JR, Merrill EH: Demography of a harvested population of wolves (Canis lupus) in west-central Alberta, Canada. Can J Zool 2011, 89:744-752.
59. Wang $Y$, Fisher D: Dingoes affect activity of feral cats, but do not exclude them from the habitat of an endangered macropod. Wildl Res 2012, 39:611-620

60. APVMA: Review Findings for Sodium Monofluoroacetate: The Reconsideration of Registrations of Products Containing Sodium Monofluoroacetate and Approvals of their Associated Labels, Environmental Assessment. Canberra: Australian Pesticides and Veterinary Medicines Authority; 2008.

61. Glen AS, Gentle MN, Dickman CR: Non-target impacts of poison baiting for predator control in Australia. Mammal Rev 2007, 37:191-205.

62. Fenner $\mathrm{S}$, Körtner $\mathrm{G}$, Vernes K: Aerial baiting with 1080 to control wild dogs does not affect the populations of two common small mammal species. Wildl Res 2009, 36:528-532.

63. Dexter N, Ramsey DSL, MacGregor C, Lindenmayer D: Predicting ecosystem wide impacts of wallaby management using a fuzzy cognitive map. Ecosystems 2012, 15:1363-1379.

64. Kennedy MS, Baxter GS, Spencer RJ: Towards a more detailed understanding of habitat: the responses of bush rats to manipulation of food and predation after fire. In The 10th Biennial Australasian Bushfire Conference: Bushfire 2006; Brisbane. SEQ Fire \& Biodiversity Consortium; 2006.

65. Moseby KE, Hill BM, Read JL: Arid recovery - a comparison of reptile and small mammal populations inside and outside a large rabbit, cat, and fox-proof exclosure in arid South Australia. Austral Ecology 2009, 34:156-169.

66. Allen BL, Engeman RM, Allen LR: Wild dogma I: an examination of recent "evidence" for dingo regulation of invasive mesopredator release in Australia. Current Zoology 2011, 57:568-583.

67. Finke DL, Denno RF: Predator diversity dampens trophic cascades. Nature 2004, 429:407-410.

68. Hairston N, Smith F, Slobodkin L: Community structure, population control and competition. Am Nat 1960, 94:421-425.

69. Choquenot D, Forsyth DM: Exploitation ecosystems and trophic cascades in non-equilibrium systems: pasture - red kangaroo - dingo interactions in arid Australia. Oikos 2013, 122:1292-1306.

70. Allen BL: A comment on the distribution of historical and contemporary livestock grazing across Australia: implications for using dingoes for biodiversity conservation. Ecological Management \& Restoration 2011, 12:26-30.

71. Carwardine J, O'Connor T, Legge S, Mackey B, Possingham HP, Martin TG: Prioritizing threat management for biodiversity conservation. Conserv Lett 2012, 5:196-204.

72. Mech LD: Is science in danger of sanctifying the wolf? Biol Conserv 2012, 150:143-149.

73. Marris E: Rethinking predators: legend of the wolf. Nature 2014, 507:158-160.

74. Kinnear JE, Krebs CJ, Pentland C, Orell P, Holme C, Karvinen R: Predator-baiting experiments for the conservation of rock-wallabies in Western Australia: a 25-year review with recent advances. Wildl Res 2010, 37:57-67.

75. Holt RD, Huxel GR: Alternative prey and the dynamics of intraguild predation: theoretical perspectives. Ecology 2007, 88:2706-2712.

76. Corbett L, Newsome AE: The feeding ecology of the dingo. III. Dietary relationships with widely fluctuating prey populations in arid Australia: an hypothesis of alternation of predation. Oecologia 1987, 74:215-227.

77. Caughley G: Analysis of Vertebrate Populations. Reprinted with Corrections Edn. Chichester: John Wiley \& Sons Ltd; 1980.

78. Burbidge AA, McKenzie NL: Patterns in the modern decline of Western Australia's vertebrate fauna: causes and conservation implications. Biol Conserv 1989, 50:143-198.

79. Lunney D: Causes of the extinction of native mammals of the western division of New South Wales: an ecological interpretation of the nineteenth century historical record. Rangel J 2001, 23:44-70.

80. Smith PJ, Pressey RL, Smith JE: Birds of particular conservation concern in the western division of New South Wales. Biol Conserv 1994, 69:315-338.

81. Brook LA, Johnson CN, Ritchie EG: Effects of predator control on behaviour of an apex predator and indirect consequences for mesopredator suppression. J Appl Ecol 2012, 49:1278-1286.

82. Colman NJ, Gordon CE, Crowther MS, Letnic M: Lethal control of an apex predator has unintended cascading effects on forest mammal assemblages. Proc R Soc B Bio/ Sci 2014, 281. doi:10.1098/rspb.2013.3094.

83. Letnic M, Koch F, Gordon C, Crowther M, Dickman C: Keystone effects of an alien top-predator stem extinctions of native mammals. Proc $R \operatorname{Soc} B$ Biol Sci 2009, 276:3249-3256.

84. Wallach AD, O'Neill AJ: Threatened species indicate hot-spots of top-down regulation. Anim Biodivers Conserv 2009, 32:127-133. 
85. Allen LR: Best-practice Baiting: Evaluation of Large-scale, Community-based 1080 Baiting Campaigns. Toowoomba: Robert Wicks Pest Animal Research Centre, Department of Primary Industries (Biosecurity Queensland); 2006.

86. Reddiex B, Forsyth DM: Control of pest mammals for biodiversity protection in Australia. II. Reliability of knowledge. Wildl Res 2006, 33:711-717.

87. Engeman $R$ : Indexing principles and a widely applicable paradigm for indexing animal populations. Wildl Res 2005, 32:202-210.

88. Engeman R, Pipas M, Gruver K, Bourassa J, Allen L: Plot placement when using a passive tracking index to simultaneously monitor multiple species of animals. Wildl Res 2002, 29:85-90.

89. Allen BL, Allen LR, Engeman RM, Leung LK-P: Reply to the criticism by Johnson et al. (2014) on the report by Allen et al. (2013). Frontiers in Zoology 2014, accessed 1st June 2014: Available at: http://www.frontiersinzoology.com/content/11/11/17/comments\#1982699.

90. Mahon PS, Banks PB, Dickman CR: Population indices for wild carnivores: a critical study in sand-dune habitat, south-western Queensland. Wildl Res 1998, 25:11-22.

91. Allen LR: Best practice baiting: dispersal and seasonal movement of wild dogs (Canis lupus familiaris). In Technical Highlights: Invasive Plant and Animal Research 2008-09. Brisbane: QLD Department of Employment, Economic Development and Innovation; 2009:61-62.

92. Wicks S, Allen BL: Returns on Investment in Wild Dog Management: Beef Production in the South Australian Arid Lands. Canberra: Australian Bureau of Agricultural and Resource Economics and Sciences, Department of Agriculture, Fisheries and Forestry; 2012.

93. Fleming PJS, Allen BL, Ballard G, Allen LR: Wild Dog Ecology, Impacts and Management in Northern Australian Cattle Enterprises: A Review with Recommendations for R, D\&E Investments. Sydney: Meat and Livestock Australia; 2012

94. Braysher M: Managing Vertebrate Pests: Principles and Strategies. Canberra: Bureau of Rural Sciences, Australian Government Publishing; 1993.

95. Carwardine J, O'Connor T, Legge S, Mackey B, Possingham HP, Martin TG Priority Threat Management to Protect Kimberley Wildlife. Brisbane: CSIRO Ecosystem Sciences; 2011.

96. Dickman C, Glen A, Letnic M: Reintroducing the dingo: Can Australia's conservation wastelands be restored? In Reintroduction of Top-order Predators. Edited by Hayward MW, Somers MJ. Oxford: Wiley-Blackwell; 2009:238-269. Conservation science and practice series.

97. Glen AS: Enough dogma: seeking the middle ground on the role of dingoes. Current Zoology 2012, 58:856-858.

98. Ritchie EG, Dickman CR, Letnic M, Vanak AT: Dogs as predators and trophic regulators. In Free-ranging Dogs and Wildlife Conservation. Edited by Gompper ME. New York: Oxford University Press; 2014:55-68.

99. Mcllroy JC: The sensitivity of Australian animals to 1080 poison. II. Marsupial and eutherian carnivores. Australian Wildlife Research 1981, 8:385-399.

100. Allen LR, Fleming PJS: Review of canid management in Australia for the protection of livestock and wildlife - potential application to coyote management. Sheep and Goat Research Journal 2004, 19:97-104.

101. Mcllroy JC: The sensitivity of Australian animals to 1080 poison. IX. Comparisons between the major groups of animals and the potential danger non-targets face from 1080-poisoning campaigns. Australian Wildlife Research 1986, 13:39-48.

102. Allen L, Engeman R, Krupa H: Evaluation of three relative abundance indices for assessing dingo populations. Wildl Res 1996, 23:197-206.

103. Engeman R, Evangelista $P$ : Investigating the feasibility of a tracking index for monitoring wildlife in the Lower Omo Valley, Ethiopia. Afr J Ecol 2006, 45:184-188

104. Olifiers N, Loretto D, Rademaker V, Cerqueira R: Comparing the effectiveness of tracking methods for medium to large-sized mammals of Pantanal. Zoologia 2011, 28:207-213.

105. Engeman RM, Massei G, Sage M, Gentle MN: Monitoring wild pig populations: a review of methods. Environ Sci Pollut Res 2013, 20:8077-8091

106. Fleming P, Corbett L, Harden R, Thomson P: Managing the Impacts of Dingoes and Other Wild Dogs. Canberra: Bureau of Rural Sciences; 2001.

107. Hayward MW, Marlow N: Will dingoes really conserve wildlife and can our methods tell? J Appl Ecol, 51:835-838.
108. Allen BL: Do desert dingoes drink daily? Visitation rates at remote waterpoints in the Strzelecki Desert. Australian Mammalogy 2012, 34:251-256

109. Caughley G, Sinclair ARE: Wildlife Ecology and Management. Cambridge, Massachusetts: Blackwell Sciences; 1994

110. Cupples JB, Crowther MS, Story G, Letnic M: Dietary overlap and prey selectivity among sympatric carnivores: could dingoes suppress foxes through competition for prey? J Mammal 2011, 92:590-600.

111. Glen AS, Pennay M, Dickman CR, Wintle BA, Firestone KB: Diets of sympatric native and introduced carnivores in the Barrington Tops, eastern Australia. Austral Ecology 2011, 36:290-296.

112. Letnic M, Dworjanyn SA: Does a top predator reduce the predatory impact of an invasive mesopredator on an endangered rodent? Ecography 2011, 34:827-835.

113. Mitchell BD, Banks PB: Do wild dogs exclude foxes? Evidence for competition from dietary and spatial overlaps. Austral Ecology 2005, 30:581-591.

114. Girden ER: ANOVA: Repeated Measures (Quantitative Applications in the Social Sciences). London: Sage Publications; 1992.

115. Glass GV, Peckham PD, Sanders JR: Consequences of failure to meet assumptions underlying the fixed effects analyses of variance and covariance. Rev Educ Res 1972, 42:237-288.

116. Lindman HR: Analysis of Variance in Complex Experimental Designs. San Francisco: W.H. Freeman \& Co; 1974

117. Dickman CR, Letnic M, Mahon PS: Population dynamics of two species of dragon lizards in arid Australia: the effects of rainfall. Oecologia 1999, 119:357-366.

118. Dickman CR, Mahon PS, Masters P, Gibson DF: Long-term dynamics of rodent populations in arid Australia: the influence of rainfall. Wildl Res 1999, 26:389-403.

119. Allen LR: The Impact of Wild Dog Predation and Wild Dog Control on Beef Cattle Production. In PhD Thesis. Australia: Department of Zoology, The University of Queensland; 2005.

doi:10.1186/s12983-014-0056-y

Cite this article as: Allen et al:: Sympatric prey responses to lethal top-predator control: predator manipulation experiments. Frontiers in Zoology 2014 11:56.

\section{Submit your next manuscript to BioMed Central and take full advantage of:}

- Convenient online submission

- Thorough peer review

- No space constraints or color figure charges

- Immediate publication on acceptance

- Inclusion in PubMed, CAS, Scopus and Google Scholar

- Research which is freely available for redistribution

Submit your manuscript at www.biomedcentral.com/submit
C Biomed Central 